Illinois State University

ISU ReD: Research and eData

Theses and Dissertations

3-29-2019

\title{
"They are Supposed to be There for Me": Using Thematic Analysis to Understand Sexual Assault Disclosures in Hispanic Families
}

Alyssa M. Hernandez

Illinois State University, alyssaMH827@gmail.com

Follow this and additional works at: https://ir.library.illinoisstate.edu/etd

Part of the Communication Commons

\section{Recommended Citation}

Hernandez, Alyssa M., "'They are Supposed to be There for Me": Using Thematic Analysis to Understand Sexual Assault Disclosures in Hispanic Families" (2019). Theses and Dissertations. 1083.

https://ir.library.illinoisstate.edu/etd/1083

This Thesis is brought to you for free and open access by ISU ReD: Research and eData. It has been accepted for inclusion in Theses and Dissertations by an authorized administrator of ISU ReD: Research and eData. For more information, please contact ISUReD@ilstu.edu. 


\title{
“THEY ARE SUPPOSED TO BE THERE FOR ME”: USING THEMATIC ANALYSIS TO UNDERSTAND SEXUAL ASSAULT DISCLOSURES IN HISPANIC FAMILIES
}

\begin{abstract}
Alyssa M. Hernandez
76 Pages

The majority of research available on family communication and sexual assault disclosure is almost exclusively focused on Caucasian women (e.g., Basinger, Wehrman, \& McAninch, 2016; Fehler-Cabral \& Campbell, 2013; Orchowski, Untied, \& Gidycz, 2013; Taylor \& Norma, 2012). This is problematic because, of all cultural groups on which studies have been conducted about sexual assault reporting, Hispanics are the least likely to disclose sexual assault, although they are at high risk to experience sexual assault (Castaneda, 2018). In this study, I aimed to understand how and why survivors of sexual assault chose to disclose their experiences to their Hispanic families. Specifically, I was interested in understanding what factors survivors considered when selecting family members to be confidants, how confidant responses shaped future familial communication about sexual assault, and how/if Hispanic families experienced and managed privacy dilemmas. I conducted seven in-depth interviews with Hispanic survivors of sexual assault who both willingly and unwillingly disclosed their assault to their family. Using thematic analysis, three themes emerged related to factors in confidant selection, confidant responses, and privacy dilemmas. Implications of the study, limitations, and future research are discussed.
\end{abstract}

KEYWORDS: sexual assault, disclosure, Hispanic, family, communication, communication privacy management 
“THEY ARE SUPPOSED TO BE THERE FOR ME”: USING THEMATIC ANALYSIS TO UNDERSTAND SEXUAL ASSAULT DISCLOSURES IN HISPANIC FAMILIES

\author{
ALYSSA M. HERNANDEZ
}

A Thesis Submitted in Partial Fulfillment of the Requirements for the Degree of

MASTER OF SCIENCE

School of Communication

ILLINOIS STATE UNIVERSITY 
(C) 2019 Alyssa M. Hernandez 
“THEY ARE SUPPOSED TO BE THERE FOR ME”: USING THEMATIC ANALYSIS TO UNDERSTAND SEXUAL ASSAULT DISCLOSURES IN HISPANIC FAMILIES

\author{
ALYSSA M. HERNANDEZ
}

COMMITTEE MEMBERS:

Aimee E. Miller-Ott, Chair

Megan Hopper

Lindsey Thomas 


\section{ACKNOWLEDGMENTS}

First and foremost, I would like to thank my two sisters, Desi and Tanya. I cannot thank you enough for always loving me, supporting me, and having a bottle ready when grad school became so stressful. I would also like to thank my mom, Lisa (Liesl), and my dad, Adiel, because without them I would not exist and subsequently neither would this thesis. Dr. Aimee Miller-Ott, I cannot express how grateful I am to have had your support and guidance through this entire process. Your encouraging emails and reassuring meetings made writing a thesis, dare I say, an enjoyable experience. To my committee members, Dr. Hopper and Dr. Thomas, your input has been incredibly valuable to both my thesis and to me. Thank you so much for your help. I also want to thank Dr. Thomas' cats, Widow, Marilyn, and sweet baby Theo, for providing much needed emotional support during my intense spring break writing sessions. Dr. Varallo, I do not know where I would have ended up without your academic and life advice. Thank you for always being a Facebook message away. Rachel Laing and Nick Raes, thank you for being my best friends through grad school and putting up with my endless shenanigans. You two are troopers. Kiah Wilson, although you were never my roommate, you were always one apartment block away. Katy Biddle, you have been a ray of sunshine in my life and I will always be up for a Pub II trip with you. Finally, a world of thanks goes to my number one girl, my chihuahua Maizy. You are the light of my life and supported me even after I accidentally gave you a concussion. That's true love right there.

A. M. H. 


\section{CONTENTS}

Page

ACKNOWLEDGMENTS

CHAPTER I: INTRODUCTION 1

CHAPTER II: REVIEW OF LITERATURE

Research Gaps and Hispanic Communities $\quad 4$

Role of Media in Perceptions of Hispanics 6

$\begin{array}{ll}\text { Male Representation and Machismo } & 7\end{array}$

$\begin{array}{ll}\text { Communication Privacy Management } & 9\end{array}$

$\begin{array}{ll}\text { Three Elements of CPM } & 10\end{array}$

Family Communication, CPM, and Sexual Assault 11

$\begin{array}{ll}\text { Choosing a Confidant } & 13\end{array}$

The Influence of Positive and Negative Responses to Sexual Assault Disclosures 14

$\begin{array}{ll}\text { Victim Blaming } & 18\end{array}$

Privacy Dilemmas in Revealing Sexual Assault Information $\quad 19$

CHAPTER III: METHODS 22

$\begin{array}{ll}\text { Participants } & 22\end{array}$

$\begin{array}{ll}\text { Procedures } & 23\end{array}$

$\begin{array}{ll}\text { Data Analysis } & 24\end{array}$

$\begin{array}{ll}\text { CHAPTER IV: Results } & 26\end{array}$

Factors in Confidant Selection $\quad 26$

$\begin{array}{ll}\text { Past Talk About Sex and Sexual Assault } & 27\end{array}$

$\begin{array}{ll}\text { Cultural Values } & 30\end{array}$ 
Confidant Responses

$\begin{array}{ll}\text { Positive Responses } & 34\end{array}$

$\begin{array}{ll}\text { Negative Responses } & 36\end{array}$

Control Over Private Information 42

Lack of Rule Negotiation $\quad 43$

$\begin{array}{ll}\text { Forced Disclosures } & 45\end{array}$

$\begin{array}{ll}\text { CHAPTER V: DISCUSSION } & 48\end{array}$

$\begin{array}{lr}\text { Summary of Findings } & 48\end{array}$

$\begin{array}{ll}\text { Confidant Selection } & 49\end{array}$

$\begin{array}{ll}\text { Confidant Responses } & 50\end{array}$

$\begin{array}{ll}\text { Control Over Private Information } & 53\end{array}$

$\begin{array}{ll}\text { Theoretical Implications } & 54\end{array}$

$\begin{array}{ll}\text { Practical Applications } & 56\end{array}$

$\begin{array}{lr}\text { Limitations and Future Research } & 58\end{array}$

$\begin{array}{ll}\text { Conclusion } & 60\end{array}$

$\begin{array}{ll}\text { REFERENCES } & 61\end{array}$

APPENDIX A: RESEARCH BOARD RECRUITMENT 69

$\begin{array}{ll}\text { APPENDIX B: EMAIL RECRUITMENT } & 70\end{array}$

APPENDIX C: COUNSELING CENTER AND CULTURAL GROUP RECRUITMENT 71

APPENDIX D: FACEBOOK RECRUITMENT POST 72

$\begin{array}{ll}\text { APPENDIX E: INFORMED CONSENT } & 73\end{array}$

$\begin{array}{ll}\text { APPENDIX F: INTERVIEW PROTOCOL } & 75\end{array}$ 


\section{CHAPTER I: INTRODUCTION}

It is estimated that one out of three biological females and one out of six biological males have experienced sexual violence at some point in their lives (Centers for Disease Control and Prevention, 2017). Modern day campaigns such as the "\#MeToo" movement and "Time's Up" help to raise awareness about the prevalence of sexual assault in society. Through these movements, people advocate for the dismissal of harmful rape narratives and demand cases of assault be taken seriously from the moment people report them (Bogen, Bleiweiss, \& Orchowski, 2018). Unlike other crimes, sexual assault survivors are often required to prove to others that the crime occurred and that they had no role in provoking its occurrence (Ahrens, 2006). Although there seems to be more media coverage and conversations taking place about sexual assault, scholars have a long way to go in understanding the complex effect of assault on communicators.

An area that lacks research is how Hispanic families communicate about sexual assault before and after a disclosure takes place. It is unknown how frequently a survivor of sexual assault discloses their experiences to family members, but it is known that Hispanic women are least likely to disclose sexual assault for reasons on which researchers only speculate (Castaneda, 2018). Research available on family communication and sexual assault almost entirely focuses on Caucasian experiences, demonstrating a need for scholars to study minority experiences. Traditionally speaking, people perceive families to be safe groups to which one should feel comfortable disclosing trauma. However, studies have shown that Hispanic families tend to avoid conversations that are sexual in nature, making sexual assault disclosures nearly impossible (Villar \& Concha, 2012). Within Hispanic cultures, topics about sex and sexual assault are taboo. Since taboo topics are culturally bound, it is important to understand what 
climate is established within a Hispanic family towards sexual assault which may hopefully lead to more open family communication.

In the thesis, I am looking to better understand sexual assault disclosure and Hispanic family communication. Researchers point out that sex and sexuality is engrained in culture and family (Villar \& Concha, 2012). The way a family talks about sexual assault prior to a disclosure could impact the way a survivor discloses their experiences to family members. Similarly, a survivor's disclosure could play a role in the way a family communicates about sexual assault. With societal attitudes toward sexual assault vastly changing and becoming more sympathetic, it is necessary to understand if Hispanic family attitudes are adjusting or if these conversations are consistently avoided. 


\section{CHAPTER II: REVIEW OF LITERATURE}

Families often play a large role in the communication patterns people develop (Ahrens, 2006). Communication privacy management theory (CPM) states that privacy orientations emerge from family environments (Petronio, 2002), meaning that families create an individual's privacy orientation based on the family's attitudes toward privacy and openness. Family is the primary agent responsible for teaching children how to manage their own private information (Bridge \& Schrodt, 2013). Petronio (2002) states that culture impacts privacy and the rules that surround disclosing private information; family and culture heavily influence if, when, and how a person discloses private information. Families also largely influence the way one communicates, views, and copes with traumatic experiences such as sexual assault (Orchowski \& Gidycz, 2013), yet there is little research demonstrating the process of sexual assault disclosure to families or the outcomes of disclosing sexual assault to families.

Families play an important role in the process of recovering and healing from trauma. Lopez-Zeron and Blow (2016) argued that

although sorting out the intrapersonal chaos caused by traumatic experiences is essential for healing, trauma is also a relational event that affects the individual survivor's inner state and their web of close relationships. Positive family support is often central to the survivor's recovery environment. (p. 581)

The way a family responds to a disclosure of sexual assault impacts the person who experienced it and could change the way families communicate entirely. Much of the research available about trauma and families focuses on death and mental health (e.g., Basinger, Wehrman, \& McAninch, 2016; Toller \& McBride, 2013). Because family communication plays a role in coping with sexual assault, it is important to uncover the role that prior communication about sexual assault 
plays in the way one discloses to a family member, if and how family responses shape the way families communicate, and if and how families' responses influence a survivor's relationship with them.

This study could produce practical application by uncovering ways that Hispanic families communicate in response to sexual assault disclosures that both aid and hinder a survivor's coping. This study can also produce practical application by identifying what factors a Hispanic survivor considers before disclosing to a family member. By better understanding what factors play a role in disclosing sexual assault within Hispanic families, it can aid families in having more supportive conversations about family member's experiences post disclosures. If family members become more comfortable and competent in talking about assault, survivors may choose to come forward with their experiences more often, likely increasing reporting. In the following review of literature, I provide the CPM theoretical framework that will guide this research, address available research on Hispanic families and sexual assault disclosures, and propose research questions to fill gaps identified in research. Further, this study gives survivors of sexual assault an opportunity to tell their story that can help others in their community while at the same time remaining confidential. Being able to share one's story can be a cathartic and helpful experience to process trauma (Lopez-Zeron, 2016). Interviewees who lack family support may find the process of sharing their experiences to be particularly helpful, especially if their family was not willing to listen to their disclosure or believe them.

\section{Research Gaps and Hispanic Communities}

Most research on family communication and sexual assault disclosure is focused almost exclusively on Caucasian women (e.g., Basinger, Wehrman, \& McAninch, 2016; Fehler-Cabral \& Campbell, 2013; Orchowski, Untied, \& Gidycz, 2013; Puretti \& Chesebro, 2015; Taylor \& 
Norma, 2012). This points to a gap in research, which is a focus on racial minorities and their experiences of disclosing sexual assault to family members. In this study, I exclusively sought Hispanic individuals to participate. The term Hispanic was strategically chosen over other identifying terms such as Chicano or Latinx. The term Hispanic refers to a person who is native of or who descends from any Latin American country (Genial, 2017). The term Hispanic has traditionally been used to describe Americans who identify themselves as being of a Spanishspeaking background and, regardless of race, trace their origin to Spanish-speaking countries, including Mexico, Puerto Rico, Cuba, Central and South America (Herrera, Owens, \& Mallinckrodt, 2013), whereas Latino/a refers to a person from Spain and Latinx is an Americanborn Latin. In order to not restrict participants due to their racial identity, the term Hispanic was more appropriate and inclusive for this study.

Studies show that minority women are more likely to experience sexual assault but are less likely to report it in comparison to biological White women. Hispanic women, in particular, are least likely of all biological women to report cases of sexual assault (Castaneda, 2018; Taylor \& Norma, 2013; Villar \& Concha, 2012). The reasons to this are unknown but it is speculated that family communication plays a heavy role due to patriarchal family structures that prohibit any conversations about sex. Villar and Concha (2012) reported that Hispanic families experience high levels of discomfort when it comes to sex communication. They state that Latinas are particularly disadvantaged communicating openly about sex. I speculate that these attitudes make it difficult to disclose cases of sexual assault. Due to a lack of minority-focused research available, this study will contribute much needed information about how Hispanics communicate with their families about private information like sexual assault. Although there is a lack of research on the Hispanic community and sexual assault disclosures, there are many 
studies on the Hispanic community and media portrayal. Media portrayals have a power over perceptions of the Hispanic community which may invalidate experiences such as sexual assault.

\section{Role of Media in Perceptions of Hispanics}

Although Hispanics make up one of the largest ethnic groups in the United States, they are infrequently and inaccurately represented in the mass media (Mastro \& Tukachinsky, 2012). Researchers speculate that the mass media play a role in disadvantaging the Hispanic community when it comes to disclosing cases of sexual assault since Hispanics are often stereotyped (e.g., Mastro, Behm-Morawitz, \& Ortiz, 2012; Mastro \& Behm-Morawitz, 2005). Exposure to stereotypes of Hispanics shapes the way the community is viewed from those who are Hispanic and those outside of the community. Tukachinsky, Mastro, and Yarchi (2017) state that "given that exposure to mass media content can shape perceptions about a group's status and value in society, influence intergroup dynamics, and impact individual self-concept, exploring this association is both theoretically and practically meaningful” (p. 539). Mastro et al. (2007) believe that exposure to inaccurate media portrayals distort what experiences are seen as valid and plausible for this community, particularly when it comes to Hispanics being victims of crime.

Traditionally, Hispanics have been frequently restricted in their representation in media and are often seen as unfavorable. Hispanics are represented as criminals, exotic lovers, sex objects, and blue-collar workers and are often presented as being unintelligent (e.g., Tukachinsky et al., 2017; Mastro et al., 2007). Rarely are Hispanics shown as being victims of crime although they are likely to be victims of crime. Because Hispanics are not often seen as victims of crime in media depictions, it is possible that their experiences are not taken as seriously as other ethnic communities. Hispanic women tend to be portrayed in the media as a Latin-lovers, Harlots, or 
sex workers. These portrayals perpetrate the societal myth that Hispanic women cannot be sexually assaulted as they are considered to be sexually aggressive and provocative (Masto \& Behm-Morawitz, 2005). They are portrayed as constantly wanting to engage in sexual acts. This harmful stereotype may speak to why Hispanic women are less likely to disclose or report their experiences of sexual assault. If families are not willing to talk about sexual assault and it is not represented in the media, an individual may think it is not possible for them to experience sexual assault. Sexual assault victims may also be lacking the communicative tools needed to handle this sensitive information.

\section{Male Representation and Machismo}

Hispanic males are represented differently than Hispanic females but equally restrictive and unfavorable. Tukachinsky et al. (2017) point out that some of the egregious portrayals of Hispanic males are slowly beginning to fade from television. For example, it is becoming less common for Hispanic males to be portrayed as unintelligent. However, Hispanic males are still commonly framed as criminals who are youthful, dishonest, and violently aggressive (Mastro \& Behm-Morawitz, 2005). Depictions of Hispanic males as blue-collar, unprofessional, and sexually aggressive also continue to thrive in the media. These portrayals perpetuate a negative image of Hispanic masculinity and reinforce toxic traditional Hispanic gender roles.

Hispanic masculinity has recently become an important area of research. Traditional machismo ideology asserts that hyper-masculinity, dominating male behavior, and heteronormativity is expected of Hispanic males. Hispanic males are supposed to prove themselves to be "men" through their masculinity and sexuality by being physically strong, tough, and having power over others, including their romantic partners (Stephens \& Eaton, 2014). These cultural expectations are particularly problematic when a Hispanic male 
experiences sexual assault. Machismo ideologies can make male survivors of sexual assault experience shame, as it is thought that they should be strong enough to fight off perpetrators. It is also commonly believed that Hispanic males cannot be sexually assaulted by women. According to machismo ideologies, men should always initiate sex and dominate women during sex, making it seem impossible for men to be assaulted by women (Stephens, Eaton, \& Boyd, 2017). This cultural belief translates to the idea that if men have engaged in sexual activity, they wanted it. Machismo rules out the possibility of men being assaulted. Machismo expectations can be internalized and be a barrier to Hispanic males disclosing and reporting cases of sexual assault. Machismo ideology has been linked to a variety of mental health problems for Hispanic males such as low self-esteem, anxiety, and depression (O-Neil, 2008). In contrast to machismo, there is caballerismo. Caballerismo is a framework that paints Hispanic masculinity in a positive light. Stephens et al. (2017) states that caballerismo ideology values chivalry, respect, and emotional expressiveness and prioritizes interpersonal relationships. Hispanic men who endorse caballerismo rank higher than machismo men on scales of satisfaction in terms of family relationships, positive feelings of self, overall life satisfaction, and satisfaction with social support (e.g., Arciniega et al., 2008; Estrada \& Arciniega, 2015). The acceptance of caballerismo is beneficial to Hispanic men for an array of reasons. Caballerismo can aid in disproving the machismo myth that Hispanic men cannot be sexually assaulted. Caballerismo can also help ensure that survivors are believed by male confidants. Caballerismo also proves beneficial to survivors, regardless of biological sex, in that they are more likely to have a more understanding response when disclosing. Although beneficial, caballerismo is still not commonly portrayed in media (O-Neil, 2008). 
The Hispanic community is disadvantaged when disclosing sexual assault for many reasons. Most researchers have focused on Caucasian populations when examining sexual assault disclosures. Since Hispanic women are least likely to disclose sexual assault, there is a need to address the research gap. Hispanics have reported high feelings of discomfort when discussing sex and sexual assault. This is attributed to inaccurate stereotypes of Hispanics through the media as well as harmful machismo ideologies. To further understand the Hispanic community and sexual assault disclosures, research should focus on how survivors of sexual assault manage private information in their families. Communication privacy management (Petronio, 2002) is an appropriate theoretical framework for this study due to its focus on private information.

\section{Communication Privacy Management}

Communication privacy management $(\mathrm{CPM})$ is a communication theory that attempts to understand how people navigate disclosing and keeping private personal information (Petronio, 2007). According to Finkenauer, Engels, Branie, and Meeus (2004), self-disclosure is an essential communicative aspect of building and maintaining healthy relationships. They define self-disclosure as "a verbal exchange that takes place when one shares information about the self, including general personal statements, dispositions, experienced events, and plans for the future" (p. 196). CPM does not specify what information is right or wrong to disclose; rather the theory

allows for an understanding of how people manage their private and public information (Petronio \& Bantz, 1991). Because scholars and practitioners have yet to discover how Hispanic survivors of sexual assault decide to whom, how, and about what they disclose regarding their experiences, CPM will be used as the theoretical framework for this study. 


\section{Three Elements of CPM}

Petronio (2013) recently streamlined CPM theory to focus on three elements, eliminating the five guiding principles of the theory. The three elements are (1) privacy ownership, (2) privacy control, and (3) privacy turbulence. Petronio (2013) states that within these three elements are eight axioms that provide additional guidance in making predictions about how people enact management of their private information. These elements provide a basis for understanding behaviors, decisions, and vital changes in managing private information.

Privacy ownership contains two axioms. Axiom \#1 predicts that people are the sole owners of their own private information (Petronio, 2013). They have the right to grant or deny access to private information. Survivors of sexual assault likely perceive information about the assault as something they own and that they can choose to share with others or not. Axiom \#2 predicts that when an original owner of private information allows access, they have authorized a confidant of information. Survivors likely try to select confidants who they trust with their private information.

The second element of CPM is privacy control. Privacy control demonstrates that sharing private information comes with rules that owners expect confidants to follow (Petronio, 2013). For example, the survivor may not explicitly say not to share their disclosed information. They may assume that their confidant will not tell others. Axiom \#3 and Axiom \#4 predict that the "original owner" may feel a need for control over their information. Consequently, they develop privacy rules for confidants. Rules develop from motivations, cultural values, and situational needs (Petronio, 2013). Petronio (2002) states that culture and gender impact privacy management. Hispanic cultures tend to have several patriarchal subtleties, in comparison to other races, which can hinder disclosing private information (Brown, 2006). These patriarchal beliefs 
may also dictate who a survivor chooses as their confidant in these families. This suggests that Hispanic family rules for private information may differ based on their cultural values.

Axiom \#5 predicts that confidants of private information will successfully maintain rules, meaning that confidants will not share the information with parties unapproved by the survivor. For example, a survivor may explicitly ask a confidant to not share their disclosure with a parent or other authority figure if they predict a negative response. Axiom \#6 predicts co-ownership of information leads to jointly held privacy boundaries that confidants utilize when sharing private information with others. The survivor believes that confidants mutually understand the rules surrounding their disclosure and expect all confidants to respect those rules. Axiom \#7 predicts that collective privacy boundaries are regulated when owners determine how much others know about the private information and who has the right to disclose it, meaning that the survivor should be in charge of deciding the number of confidants a survivor has and how much information they know.

Privacy turbulence is the third and final element of CPM theory. Axiom \#8 predicts that privacy regulation is unpredictable, and disruptions can occur, creating a small or large amount of damage to the original owner. (Petronio, 2013). Privacy turbulence is the range of distress the original owner endures when a confidant breaks rules attached to private information. Ideally, confidants would follow and avoid breaking the rules. However, in instances when confidants share information with someone who is not approved by the survivor, privacy turbulence occurs between the survivor and the confidant.

\section{Family Communication, CPM, and Sexual Assault}

Family communication scholars have used CPM to study privacy management related to many different traumatic experiences. The loss of a family member is a complicated trauma that 
is difficult information for families to manage (Basinger et al., 2016). In their investigation of family members' disclosures, Basinger et al. (2016) found that families strategically chose confidants who had lost a family member themselves and would be familiar with their grief communication. They perceived empathetic confidants as more understanding of privacy rules, which lowered the risk of privacy turbulence. By avoiding privacy turbulence, families explained they could better process their trauma. Families may also shift their privacy orientation when coping with trauma. Toller and McBride (2013) researched parents who chose to disclose the death of a family member to their children, resulting in a privacy orientation shift. The researchers found that parents desired to create new privacy rules that they believed would result in open communication between themselves and their children. Disclosures had to be well thought out ahead of time, and parents were very selective of which information to reveal and conceal. Parents hoped that disclosure of a family death would help their children develop privacy management skills (Toller \& McBride, 2013).

Communication scholars have rarely focused on privacy management and sexual assault disclosures in families, and to an even lesser extent, talk about sexual assault in minority families. In one study by Kennedy-Lightsey and Frisby (2016), they discovered that families who encourage openness and individuality tend to have an easier time processing a disclosure of sexual assault than families who discourage openness and perpetuate parental authority. Survivors in those families were less likely to disclose any private information about the assault. Survivors in families with a high-conversation orientation were more likely to self-disclose to family members than those in low conversation-oriented families. These findings underscore the importance of open conversations in family spaces to create a comfortable environment in which one can self-disclose sexual assault. These findings also suggest that perhaps how a family 
communicates about the topic of sexual assault may impact how a survivor interprets and discloses their own experience. Because there is scant research available that explores how Hispanic families communicate about sexual assault prior to an assault, the role that conversations play in self-disclosing, and how openness may shape the way a disclosure takes place, I pose the following research question:

$\mathbf{R Q}^{\mathbf{1}}$ : How, if at all, do Hispanic family conversations about sexual assault, prior to a sexual assault taking place, play a role in whether and to whom a survivor discloses within the family?

\section{Choosing a Confidant}

CPM establishes that privacy management is a collaborative process. To whom a survivor discloses is an important and difficult decision. According to CPM, when survivors choose to disclose their experiences to another person, those people become confidants and are now co-owners of the information. According to Petronio (2010), a confidant is a person who a survivor trusts and to whom they share private information. Confidants are expected to follow rules that the survivor puts on sensitive information whether they be implicit or explicit rules. The available research on sexual assault disclosures rarely focuses on family disclosures or why a survivor would disclose to a family member in comparison to other confidants. Studies tend to focus on family and romantic relationships or family and school administration disclosures instead of solely focusing on family disclosures. (e.g., Ahrens, 2006; Alexander, 1980; FehlerCabral \& Campbell, 2013). Survivors of sexual violence often feel a need to disclose their experiences to someone with whom they are close (Harvey, Orbuch, Chwalisz, \& Garwood, 2001). Pluretti and Chesebro (2015) found that survivors choose to disclose to a person with whom they can identify on some level. Survivors of sexual assault are more likely to report 
positive experiences of self-disclosure if they and their confidants have similar personalities (Botta \& Pingree, 1997).

Biological sex may also influence selection of a confidant. Finkenauer et al. (2004) suggested that self-disclosure is more likely to occur in families when the discloser and confidant are the same biological sex. This is especially true within Hispanic families. Villar and Concha (2012) stated that biological sex may a play a large role in Hispanic families when it comes to taboo topics like sex and sexual assault. Typically, mothers talk to daughters and fathers talk to sons about taboo topics. With biological sex matching, family members feel less discomfort in talking about sex. I speculate that this may be true for disclosures of sexual assault. Apart from these factors that influence confidant selection, we know very little about why survivors might choose to disclose to their family member(s) over others. Therefore, I propose the following research question:

$\mathbf{R Q}^{2}$ : What, if any, specific factors do survivors take into consideration when choosing to disclose to a family member over other potential confidants?

\section{The Influence of Positive and Negative Responses to Sexual Assault Disclosures}

Scholars frequently find that self-disclosure is an instrumental part of recovery from experiences of sexual trauma (e.g., Ahrens, 2006, Botta \& Pingree, 1997; Orbuch, Harvey, Davis, \& Merbach, 1994; Puretti \& Chesebro, 2015, Taylor \& Norma, 2012). However, the way a confidant responds to a survivor's disclosure plays an important role in how well the survivor recovers (Orchowski et al., 2013), reflecting the more collaborative nature of CPM. When a sexual assault survivor discloses their trauma, they may interpret a response as positive or negative. A positive response to a sexual assault disclosure may mean that a confidant is understanding, sends messages of validation, and makes the survivor feel supported. When a 
survivor receives a positive response, their physical and psychological health may improve, and they may be more proactive in seeking medical care for their assault (Orbuch et al., 1994). Confidants who validate experiences and help the survivor seek resources help promote a healthier recovery for a survivor (Ullman, Filipas, Townsend, \& Starzynski, 2007). Acts of support also increase the likelihood of survivors communicating with authorities about their assault (Ullman et al., 2007).

When choosing to engage in a disclosure about sexual assault, survivors may worry that their self-disclosure will elicit a negative response from family members. Negative responses may lack support and validation for the survivor. Negative responses may elicit feelings of shame and blame instead of understanding. Researchers state that absence of a response is also considered a negative experience for survivors (Taylor \& Norma, 2013). The fear of a negative response can force survivors to refrain from communicating about their trauma (Durham, 2008). In fact, it is common for survivors to receive what they perceive as negative reactions to their self-disclosures. Ahrens, Cabral, and Abeling (2009) attempted to understand the prevalence of negative reactions to sexual assault disclosures to family, friends, or romantic partners. Ahrens et al. (2009) found that $75 \%$ of female survivors receive some form of negative response to their sexual assault disclosures and 20\% expressed regret in disclosing their assault. Survivors considered fear of rejection, not being believed, and possibility of victim blaming when choosing whether or not to disclose about their assault (Middleton, McAninch, Pusateri, \& Delaney, 2016). The prevalence of negative responses presents survivors with many reasons to be hesitant about self-disclosure, even to family members.

Researchers (e.g., Castaneda, 2018; Villar \& Concha, 2012) state that Hispanic families have negative responses to disclosures of sexual assault due to a variety of reasons. Hispanic 
families tend to identify as a collectivist culture. Due to their collectivist culture, Hispanic families are thought to see sexual abuse as not happening to one individual but rather to the whole family (Castaneda, 2018). A negative response from a family member may stem from that family member feeling personally hurt or angry. Religion may play a role in negative responses survivors receive from their families. Hispanic families typically follow Catholicism in comparison to Christianity, which is more popular in the United States. Catholicism puts value on virginity, particularly for young biological women (Castaneda, 2018). I speculate that loss of virginity plays a role in whether a survivor discloses and to whom in a Hispanic family.

Most survivors expect positive emotional support from family members (Fehler-Cabral \& Campbell, 2013). Taylor and Norma (2012) argued that negative reactions from family members are particularly damaging to a survivor's recovery and "can deeply affect the confidence of a survivor to disclose further and report the crime" (Taylor \& Norma, 2012, p. 5). These attitudes work to diminish open communication about sexual assault, creating fear and stigma for those who wish to disclose their experience (Bogen et al., 2018). Survivors of an assault perpetrated by a family member face unique disclosure risks (Taylor \& Norma, 2012). These survivors struggle more to recover than non-familial survivors (Harvey et al., 1991). Biological females assaulted by family members are less likely to cope with their trauma through healthy communicative methods (Orbuch et al., 1994). They are less likely to self-disclose and are more likely to selfblame for a variety of reasons (Orbuch et al., 1994).

Survivors of familial assault fear ostracism, not being believed, and bringing shame to their families if they disclose their experiences (Taylor \& Norma, 2012). They believe that disclosing their assault will burden their family legally and tarnish the family's reputation. Brown (2006) states that shame, defined as "an intensely painful feeling or experience of 
believing we are flawed and therefore unworthy of acceptance and belonging” (p. 45), plays a prevalent role in families. Shame is a psycho-social cultural construct that is created from interpersonal relationships (Brown, 2006). The prevalent role of culture in the concept of shame demonstrates a failure to reach cultural expectations. Catholicism often influences the conservative expectations for women in Hispanic culture (Wamsley, 2014). An example of this would be marianismo. Marianismo ideology prescribes Hispanic women to be moral, sexually pure, and submissive to their male counterparts, and encourages vulnerability, which is deeply rooted in Hispanic culture (Eaton et al., 2016). This conservative ideology highly values virginity for Hispanic women. If a sexual assault results in one "losing" their virginity, they may be bringing shame upon their family as they violated their marianismo expectations.

Most survivors described a fear of the perpetrator as the primary barrier to disclosure. Family perpetrators had easy access to the survivors and often utilized threats of physical harm to keep survivors from disclosing abuse (Taylor \& Norma, 2012). The other family members trivialized and failed to validate the survivors' experiences. These insensitive responses often resulted from misconceptions of sexual assault and societal stereotypes of rape. Hispanic families tend to focus on fatherhood and patriarchal beliefs (Rafanello, 2004). Due to the masculine nature of these families, a family perpetrator may bring a larger amount of shame. This is because males of the family should prevent sexual assault from occurring, potentially provoking a negative response.

Even when not experiencing sexual assault from a family member, survivors may experience "second victimization" as a barrier to self-disclosure (Ahrens, 2006). Second victimization is a social phenomenon that occurs when recipients of disclosures doubt the severity of the crime, believe the survivor provoked the crime, or deny the survivor necessary 
services for the crime (Ahrens, 2006). "Speaking out about the assault may therefore have detrimental consequences for rape survivors as they are subjected to further trauma at the hands of the very people they turn to for help" (Ahrens, 2006, p. 264). Survivors hope for positive responses to their sexual assault disclosures; thus, when they experience further victimization, doubt, and other negative responses, feelings of distrust may cultivate or further grow between the survivor and their family. When a confidant responds negatively to a survivor's disclosure, the survivor can experience feelings of distrust and self-silencing (Harber, Williams, \& Podolski, 2015). Self-silencing survivors are less likely to report their assault to authorities or seek social support to overcome their trauma (Gray, Palileo, \& Johnson, 1993). These feelings may put a strain on the relationship a survivor has with their family. Little research exists on how Hispanic survivors are impacted by positive and negative responses to their disclosures. Therefore, I proposed the next research question:

$\mathbf{R Q}^{3}$ : How, if at all, do positive/negative responses from family members play into future talk about the assault?

\section{Victim Blaming}

A common negative response to sexual assault disclosures is victim blaming. Victim blaming is the communicated belief that a survivor of sexual assault is somewhat or entirely responsible for their experience (Hayes, Lorenz, \& Bell, 2013). Survivors risk experiencing victim blaming the moment they disclose their assault to a family member. The communicative act of victim blaming has an immensely negative effect on a survivor's ability to heal from sexual trauma. Survivors often internalize victim blaming as self-blame. Sheikh and McNamara (2014) found that survivors who experience self-blame face unpleasant emotions such as regret, 
shame, and guilt. They also experience a heightened risk of developing anxiety, depression, and posttraumatic stress disorder.

Studies found that societal rules, norms, and beliefs shape victim blaming attitudes (Alexander, 1980). Attitudes towards women play an important role when assigning blame to victims of assault. Biological women are more likely than biological men to be victim blamed based on their behavior during an assault (Eigenberg \& Policastro, 2016). Women who are assaulted by a stranger are less likely to experience victim blaming (Sleath \& Bull, 2010). However, the likelihood of victim blaming increases if a friend or acquaintance is the assailant, playing into the idea that women lead others on or that they are asking for it (Bernard, 2015). Survivors who are blamed when disclosing to family members experience deeply hurt feelings and distrust (McKibbin, Humphreys, \& Hamilton, 2017). Previous research focuses on the shortterm effects a survivor experiences when victim blamed by family members. It is beneficial to look at possible long-term effects that survivors perceive if they experience victim blaming by their families. Thus, I pose the following questions:

$\mathbf{R Q}^{4 a}$ : How, if at all, does victim blaming emerge in responses to sexual assault disclosure?

$\mathbf{R Q}^{\mathbf{4 b}}$ : What role do instances of victim blaming play in the perceived quality of the relationship between the survivor and their family?

\section{Privacy Dilemmas in Revealing Sexual Assault Information}

Because of the risky nature of disclosing sexual assault to family members, members may grapple with appropriate levels of privacy and openness, thus creating tension (Petronio, 2010). CPM theory refers to this tension as a privacy dilemma, or 
predicaments that provoke communication tension within families with no clear solution. Family members often rely on each other as confidants to disclose to. When information is unsettling, family members may feel trapped by the information as they are unaware of what do with it. (p. 189)

Oftentimes, privacy dilemmas result in conflict among family members (Petronio, 2010). Conflict causes a strain on family relationships which can have a negative impact on a member who is healing from trauma (Lopez-Zeron \& Blow, 2016).

Petronio (2010) points out that researchers have only scratched the surface of privacy dilemmas. Researchers have identified three different ways in which families experience privacy dilemmas, although Petronio points out there are many undiscovered privacy dilemmas. First, families can experience a confidant privacy dilemma. This type of dilemma occurs when one family member reveals an incident to another member that demands action (Petronio, 2010). The dilemma is from the perspective of the confidant who may grapple with what the next step should be. The second is an accidental privacy dilemma meaning that family members inadvertently learn private information about another family (Petronio, 2010). An accidental privacy dilemma could be overhearing a conversation that reveals private information. The third privacy dilemma an illicit privacy dilemma in which a family member snoops or spies to gain access to private information (Petronio, 2010).

It is concerning that privacy dilemmas are solely confidant-focused. Petronio (2010) explains that privacy dilemmas are co-created between a discloser and a confidant when private information is told. This leaves one to ask if disclosers of private information can experience a privacy dilemma. Scholars have attempted to explore the ways in which families overcome privacy dilemmas. Current research explores negative experiences such as divorce, drug 
addiction, and healthcare concerns (e.g., Petronio 2010; Petronio, Sargent, Andea, Reganis, \& Cichoki, 2004). It is ideal for families to manage, and if possible overcome, privacy dilemmas when coping with sexual assault disclosures. However, Petronio (2002) notes that culture dictates how families cope with privacy, privacy dilemmas and the concept of privacy itself. Petronio (2010) suggests that the best way families can cope with privacy dilemmas is through management strategies that help them to coordinate new privacy rules. Coordinating new privacy rules occurs through conversations between all owners of the information. Petronio (2010) also believes that management strategies can be instilled in family members throughout their lifetime. For example, some families stress that family business is family business, meaning that private information should never spread outside the family. However, coping with privacy dilemmas has only been researched in very specific contexts and none related to sexual assault. It is unknown how survivors of sexual assault experience privacy dilemmas and how survivors respond to them. This gap in research leads to the next research questions:

$\mathbf{R Q}^{5 a}$ : What, if any, privacy dilemmas do Hispanic survivors of sexual assault experience with their families?

$\mathbf{R Q}^{\mathbf{5}}$ : If privacy dilemmas do occur, how do survivors and their families manage them?

This literature review demonstrated that there are many gaps in communication research regarding sexual assault disclosures in Hispanic families that must be filled to gain insight into this context. CPM provided a useful framework for understanding the relationship between sexual assault disclosures and Hispanic family communication. Qualitative interviews, rarely used in sexual assault disclosure research, provide opportunities to gain an in-depth understanding of a survivor's communicative experiences of disclosing to family members. 


\section{CHAPTER III: METHODS}

A qualitative research design was the best method to answer my research questions. Qualitative methods capture the varying complex nature of human experiences (Guba, 1978). Qualitative research is also ideal for identifying underlying meanings and patterns within interpersonal relationships (Rubin \& Rubin, 2012). Due to the complexities that survivors of sexual assault typically experience, qualitative interviews were the most appropriate method for this study.

\section{Participants}

I conducted seven qualitative in-depth interviews with Hispanic survivors of sexual assault. Criterion sampling helped to provide interviews that were information-rich and relevant to the research topic (Lindlof \& Taylor, 2011). Criterion sampling helped ensure that the participants selected were the best candidates for this study. Participants had to identify racially as Hispanic, be at least 18 years old, have disclosed an experience of sexual assault to at least one family members, and be comfortable speaking about their experiences. Before interviewing, I obtained IRB approval. Participants' age at the time of their assaults varied, ranging from 20 to 25 years old. Six of the seven participants described their families as close prior to their disclosure, while one described their family as toxic. All interviewees were raised by their biological Hispanic families. Six interviewees identified as biological females and one interviewee identified as a biological male. There was a large range of sexual assault occurrences

for participants spanning from 15 years prior to the present day. How long participants waited to disclose their families ranged from one month to three years after their assaults. 


\section{Procedures}

I recruited participants through an on-campus communication research board. Additional recruitment took place via posted bulletin board flyers in an on-campus student counseling center, diversity centers on and off campus, and Hispanic community centers. I also posted information about my study on Facebook and the National Communication Association listserv. I reached out to Hispanic heritage groups on campus to ensure direct communication with Hispanics (See Appendices A through D for recruitment materials). Potential participants were required to contact me via email if they had interest in the study. Due to the sensitive topic of this study, I responded to participants' emails with a list of requirements for participants and a consent form that they had to read prior to the interview. If the participant confirmed that they fit the criteria and agreed to the consent form, we scheduled an interview. The interview may have invoked upset feelings regarding past experiences. To prevent distress, I ensured that participants were aware that they may exit the interview at any time and could leave any question unanswered. I explained this in the consent form I initially emailed to participants. Additionally, I read the consent form aloud for participants before every interview (See Appendix E for informed consent).

I used a semi-structured interview protocol (Rubin \& Rubin, 2012). I did not ask participants questions regarding their actual sexual assault(s). I informed them that I was a mandatory reporter and that if they shared information about their assaults, I was required to report the assault to the university. Instead, the interview questions focused on the participant's disclosure of assault to their family, their family's reactions, and how these conversations impacted the participant and family communication. I began the interview asking basic demographic questions (e.g., What is your age? What is your gender? Would you describe your 
family as close?). I then asked questions about how their families talked about sex and sexual assault prior to their disclosure (e.g., What messages did you receive about sex/sexual assault growing up?). The next set of questions focused on their family's responses to their disclosure of sexual assault (e.g., Who was the first family member you disclosed to and why? Which members of your family did you reveal your assault to?). The interview closed with questions about how the disclosure impacted family communication going forward (e.g., Can you identify any ways in which your family communicated with your differently after you disclosed? Do you believe your family's response to your disclosure was what you wanted at the time?). I ended interviews asking participants if there was anything they wanted to add about their family or their sexual assault disclosure (See Appendix F for interview protocol).

Interviews lasted between 30 and 60 minutes. Of the 7 interviews conducted, 3 were faceto-face, 3 were over the telephone, and 1 was completed on FaceTime. I recorded all interviews to transcribe them for analysis and deleted recordings after the transcription was complete. I gave all participants pseudonyms to maintain their confidentiality. In total, interviews yielded 112 single-spaced pages of transcripts.

\section{Data Analysis}

Thematic analysis of data is a method used for identifying, analyzing, and researching patterns and themes in a data set (Braun \& Clark, 2006, p. 79). Using thematic analysis allowed me to uncover "experiences, meanings, and the reality of participants" (p. 81) to better understand Hispanic family communication and sexual assault disclosures. To analyze my data, I used Braun and Clark's (2006) six-step process of thematic analysis. The six-step process required that I first familiarized myself with my data. Transcribing and re-reading my data fulfilled this step. The second step required me to generate a list of codes for the data that helped 
me identify potential themes. In the third step, I narrowed my list of codes into broader themes. In step four, I refined my themes. By using level one and level two reviewing, I ensured that the coding and themes accurately reflected my data (Braun \& Clark, 2006). The fifth step required me to list and define the themes I identified. The sixth step took place when I produced a final report on the data. I used CPM to guide most of my research questions. Throughout the analysis, I used concepts from CPM to help me make sense of my data and relied on thick, rick excerpts selected from my interviews to support the themes. 


\section{CHAPTER IV: RESULTS}

I identified three themes during data analysis. I have organized the following sections by the themes that corresponded with each of the five research questions. Some themes represented multiple research questions. The three themes I identified were factors in confidant selection, confidant responses, and control over private information. I first explain the theme and then utilize selected portions of participant responses to further illustrate their experiences.

\section{Factors in Confidant Selection}

In CPM, Axiom \#2 predicts that original owners of private information select a confidant to whom to disclose private information. Selecting a confidant is a difficult decision, and people often weigh certain factors when making decisions about disclosures. In the first two research questions, I was interested in learning how participants decided upon confidants, specifically whether and how their family's communication about sex and sexual assault played a role in whether and to whom they disclosed within the family $\left(\mathrm{RQ}^{1}\right)$ and what other factors they took into consideration when choosing a confidant $\left(\mathrm{RQ}^{2}\right)$. As participants were deciding whether they would disclose their assault to someone in the family, two factors emerged as most important. First, in line with $\mathrm{RQ}^{1}$, they considered if and how particular family members have talked about sex and sexual assault. If the person had been open and positive about both topics in the past, they were more likely to select them as a confidant. Conversely, closedness in talking about sex and assault or framing talk about both topics as negative often signaled to the participant that the family member may not be a good confidant. Second, when examining other factors that played

a role in confidant selection $\left(\mathrm{RQ}^{2}\right)$, participants heavily weighed how much the potential confidant adhered to strict cultural values. 


\section{Past Talk About Sex and Sexual Assault}

All participants reported that they tried to predict what kind of response they would receive from their family before they disclosed their assault. Predicted responses were heavily shaped by a family's prior communication about sex and sexual assault. Numerous participants shared that their family member(s) had talked in a positive way about sex and/or were open about talking about sexual assault. For instance, Rose, a twenty-year-old female who was assaulted in high school, explained that her mom had always been direct about educating her on assault and protecting herself. "My mom had talked to us about it. I knew not to talk to anyone who I thought was predatory or things like that"- please note: numerical notations after each excerpt reflect interview number and transcript line numbers (2: 38-39, 47-49). Rose explained that her family often spoke about sexual assault after seeing cases come on the news. Her family would speak about it in a sympathetic tone. "They were disturbed and disgusted by anyone who would think of doing that action" (2: 63-64). Rose felt most comfortable disclosing to her mother, as it was her mother who often spoke of these topics to her. Similarly, Selena, a twentythree-year-old female, explained why she chose to disclose to her sister.

I told one sister because she's just someone I'm really close with and I felt comfortable confiding in her about it because she's really educated on sexual assault victims. I felt like she was someone who could provide some real emotional support. I felt like if I told my mom she was just going to be a neurotic mess and I would end up having to give her support. (1: 103-108) Due to previous conversations with her sister, Selena was confident that she would receive the positive response from her sister that she predicted and needed. 
It appeared that for many participants, they were more comfortable disclosing to someone who made sex and sexual assault part of an ongoing dialogue as they grew up. For instance, Miri, a twenty-three-year-old female participant who was assaulted when she was ten years old, explained that although she waited two years to share her assault with her mom, she chose her mom as a confidant because her mom spoke of sexual assault often: "Just like a general conversation, especially when the talk of boys started happening. It was more like this can't happen because you're a lady and you know you have parts we don't want to be disrespected" (3: 41-44, 47-48). Miri felt as though she could disclose to her mom since she had been open about sexual assault prior to her assault. As she stated, "Open communication was really what helped or else it wouldn't have come out at all" (6: 89-90). This example demonstrates that without open, ongoing communication, the disclosure may not take place.

Participants seemed to perceive emotional closeness with people who were open and positive about sex. For example, Amal, a twenty-year-old female college student was assaulted while in high school, explained that her Aunt, who was 2 years older than her, first spoke to her about sexual assault when Amal started attending high school. Her Aunt was the only family member who had talked to her about sex and assault.

Like she was always telling me about the certain guys that were, were not good people to be around. She used to take me to school sometimes, so I feel like she would just want me to be careful because there were some people at our school that were very, like, they were sexually assaulting girls in school. She just wanted to make sure I knew what to do to be safe. $(6: 49-51,58-60,62-63)$ Participants also considered whether their family was open but framed sex negatively when deciding to whom to disclose. 
Knowing how strongly they felt about it [sex] and how against it they were, I was more afraid of how strongly they would react, knowing what had happened. So, there's a give and take where you're happy that they would take your side, but you're also scared of what would happen. (3: 74-80)

Miri explained that she engaged in "testing, meaning kind of talking about it in general to see how the person that you're like choosing to disclose to would react about that situation before saying anything about your own experience" (3: 115-118). Similarly, Selena explained that her mother always had overbearing communication regarding sexual assault prior to Selena's experience. Her fear of her mother's response factored into Selena not considering her mom to be a suitable confidant, and ultimately, she never disclosed to mother. When asked what she anticipated her mother's response to be, Selena described a response that she deemed scary. I think she would have lost sleep over it. I think she would've started hysterically crying. Kind of unrealistic but I think she would have come to the city I was living in and strangle this person with her own hands. It just would have been so crazy. I didn't need that at that time. (1: 350-356).

Kennedy-Lightsey and Frisby (2016) discovered that families who encourage openness tend to have an easier time processing a disclosure of sexual assault. Openness about sexual assault prior to a disclosure was a factor that Hispanic survivors considered when in the process of selecting their family as a confidant.

Although framing sex negatively played a role in whether participants chose someone as a confidant, participants also reported that they were less likely to select a confidant who did not talk about sex and sexual assault at all. For instance, Amal 
explained that her parents had never talked to her about sex or sexual assault and thus, she would not select them as confidants.

It definitely did not make it comfortable for me to talk to my parents about it. I know that for a fact, but I definitely was able to talk about it to my Aunt. It's easier to talk with someone closer to you than somebody who doesn't tell you anything about it except what you hear all the time in media. (6: 84-87)

Prior family communication about sexual assault, or lack thereof, and how talk was framed (positive vs. negative) was frequently cited as a major reason as to why survivors selected certain family members as confidants.

\section{Cultural Values}

Participants cited an additional factor that shaped decisions about confidants. Traditionally speaking, Hispanic family attitudes about sex and sexual assault are tied to cultural values, such as machismo and marianismo ideologies. If participants perceived that their family member(s) held strong beliefs in cultural ideologies, which they believed often contributed to the member(s) communication about sex and sexual assault, participants hesitated to select those family members as confidants. Emilio, a 22-year-old male, was assaulted when he was 17. His family found out a month later about his assault when he was hospitalized for a post-traumatic stress induced panic attack. Since Emilio was a minor, he was legally required to disclose to his family. He described his family as very traditional in terms of machismo ideologies. "I was mostly raised in Mexico. The way the culture is there, you don't talk about sexual assault. It's not something that families discussed or that parents even acknowledge happens" (5: 58-61). Emilio went on the explain that his dad and step-dad made it clear that males could not experience sexual assault 
since they should be strong enough to fight off perpetrators, a machismo ideology. This played a role in the amount of fear he experienced when he had to disclose that he was assaulted. Well, I was very afraid. I was, since first of all they don't think a male can be a victim of sexual assault. When that happened to me, I saw like to some degree it was my fault. They speak of something being so impossible. It was very hard for them to grasp the idea that a male can be a victim of sexual assault. (5: 93-97, 7375)

Emilio explained that these well-known family attitudes were the most important factor to him when considering disclosing.

Similar to Emilio, Valeria, a 24-year-old female participant described her family as close but that they rarely spoke of sex or sexual assault. She explained that her family followed traditional marianismo expectations when it came to appropriate behavior regarding women and sex. Valeria was expected to maintain her virginity, avoid drinking or excessive drinking, and be more domestic. She mostly received marianismo messages from her father. "Growing up in terms of sex, it was just wait until you're married. Basically, only have sex with one person your entire life. Sexual assault, no. I didn't really hear too much of it, especially not from my parents" (7: 47-50). Valeria explained that her father's strong belief of marianismo weighed heavily on her when choosing family members as confidants. Although her father was more vocal about marianismo, it was a clear expectation within the family. These expectations resulted in her not initially selecting her father or mother as a confidant. After disclosing to others, not receiving the support she wanted, and experiencing a panic attack, she chose to disclose her assault to her parents. 
I messaged my dad first and I just felt so vulnerable. I just kept messaging him that I really needed him. I needed my mom and I knew they were busy. It was like a Sunday, so I knew they had work the next day but I just really needed them. I was like I'm completely alone and I'm just panicking, and I just need to like have that comfort. (7: 194-198)

Valeria made it clear that although she knew her father would have a negative response to her disclosure due to his previous closed off communication, she was desperate for her parent's comfort. She was very hesitant to tell her father and originally, he was not her chosen confidant. She first disclosed to friends who she felt would provide her enough support. However, she explained that she was desperate for her parents' comfort during such a traumatic time, "He had never seen me to the point of that night where I was just so desperate that I needed him" (7:250-251).

Selena knew she could never disclose to her father. She explained that cultural factors caused her father to have closed communication about or sexual assault, making disclosing uncomfortable. She perceived him to have an unsupportive response.

I just think that we've never had a close relationship and it's probably because he didn't have that and so he doesn't know how to do that. But that just ties back to Mexican culture. He grew up in Mexico, his whole family roots are there. And so if he never had it, it was probably because his parents never had it and their parents never had it. So, they never knew how to provide this type of emotional support. (1: 431-436)

In summary, families who had open and/or positive communication about sex and sexual assault prior to a disclosure were more likely to be chosen as confidants, whereas 
family members were typically not selected as confidants if they did not talk about sex or assault or if they had more negative perspectives about it. Hispanic cultural values, such as a belief in machismo and marianismo ideologies, often determined how survivors predicted a family member's response. Although participants reported that predicted responses factored into confidant selection, responses received post-disclosure played a much larger role for survivors when selecting a familial confidant.

\section{Confidant Responses}

I addressed $\mathrm{RQ}^{3}, \mathrm{RQ}^{\mathrm{a}}$ and $\mathrm{RQ} 4^{\mathrm{b}}$ by examining confidant responses. In $\mathrm{RQ}^{3}, \mathrm{I}$ inquired about how positive and negative responses from family members might play a role in future talk about assault. Participants reported that confidant responses shaped the way they perceived their sexual assault. In addition, in $\mathrm{RQ}^{4 \mathrm{a}}$, I asked whether victim blaming would emerge in their recollections of disclosures. Analysis revealed that participants were victim blamed after their disclosures and perceived that as the most negative type of response to their disclosures. Participants believed that machismo and marianismo ideologies heavily influenced victim blaming messages, and the victim blaming messages played a negative role in family relationships. At times, survivors would discontinue family relationships with those who victim blamed them $\left(\mathrm{RQ}^{4 b}\right)$. The way a confident actually responds to a sexual assault disclosure can influence a survivor in various ways (Orchowski et al., 2013). Note that this is different from perceived responses. Actual responses can shape a survivor's experience in terms of willingness to seek medical attention and disclose to others (Orbuch et al., 1994). The influence that a confidant's response has on a survivor accurately represents the collaborative nature of 
CPM because participants identified that a confidant's communicative response shapes the way they viewed themselves and their assault.

To address RQs 3 and 4, I organized the following section on confidant responses into subthemes of positive responses and negative responses and included victim blaming as the most hurtful negative response participants received.

\section{Positive Responses}

Of all survivors in the study, only one participant focused in her talk about positive responses to their disclosure that helped her come to terms with their trauma and heal from it. Positive responses also helped survivors feel as though they could openly discuss their trauma when needed to the specific confidants they chose, which they found to be cathartic and played into whether they engaged in future talk about the assault. Survivors described positive responses as supportive messages that made them feel safe and validated in their experiences. Positive responses also put responsibility on the perpetrator, not the survivor. Rose explained that the decision to disclose was very nervewracking for her, but her family's positive response helped her cope with her trauma. She was never made to feel like her assault was her fault. She described their responses as similar in terms of comfort and support. Her sister's response was particularly memorable. She recalled, "When I did tell her, we cried together, and she really just hugged me and told me that she wished I would have come to her sooner" (2: 277-279). She also found her stepmom's response to be positive.

My step mom, she's a psychology teacher, so I think she really helped explain to my dad that my brain wasn't full developed. Like it's very easy for an older man 
to manipulate younger minds and I'm really thankful for her for helping explain it. $(2: 288-291)$

Rose explained that her family's response helped the family become closer. "I definitely became much close and much more open with my family. It seemed like I had lied for so long. It was almost a relief. Like now I can tell them everything” (2: 395-398).

In terms of future talk, Rose described that her family brought up the assault to check in with her and to offer additional resources. Rose felt comfortable pursing legal action against her perpetrator, through which her family helped to guide her. She also sought out mental health resources with the help of her mom. With the help of therapy, Rose found closure and was able to heal mentally and emotionally from her assault. This example demonstrates the vital impact that positive family responses has on survivors. Positive responses to disclosures help shape future talk of assault within the family. When Rose needed to talk to her family or wanted to seek out additional resources, she felt as though she could have those conversations because of her family's positive response to her disclosure.

Although rare in the study, positive responses from confidants appeared to be instrumental in future talk about sexual assault in Hispanic families $\left(\mathrm{RQ}^{3}\right)$. When receiving positive responses to disclosures, survivors may feel as though they could openly and comfortably speak to family members about their assault in the future without judgement. As stated earlier, it is important to note that Rose was the only participant who identified her family's response as supportive and as what she wanted at the time. Most participants reported receiving negative responses to their disclosure. 


\section{Negative Responses}

Six of the seven participants recalled negative responses to their disclosure from at least one family member. These negative responses played a significant role in how survivors perceived their sexual assault experience. Survivors felt as though they could not openly talk to their families about their assault, which eliminated the possibility of future talk of such topics. Negative responses left survivors feeling a sense of responsibility over their assault, as though they had done something to cause the assault. Negative responses also left survivors feeling ignored or unimportant. Sophia described her family as nonresponsive. She explained that the lack of support she received from her mom was incredibly hurtful and not what she expected.

I told my mom and like, nothing happened. She didn’t do anything about it. Fast forward to junior year, I was asking for help and I wasn't getting the help that I needed. I mean, I was going to therapy, but I wasn't getting the support I needed from my family. And so, I don't know, things just became too much for me. And then junior year, that's when I attempted suicide and that's when things got more intense. Through the whole thing, it was me, myself and I. I had support from my teachers and my guidance counselors and my therapist. But the people who were supposed to be there for me, they weren't there for me. (4: 79-86, 91-94)

Similarly, Amal explained that her parents' response was to talk about the assault once and then never address it again, which she described as causing her to feel as though she could not bring up the topic again and made her feel ignored. She said, "My mom was very quiet about it for sure. My dad was kind of similar to my aunt's, very overprotective, but anything past that, he didn't know what to say" (6: 213-216). Her parents never again 
addressed her disclosure or asked her questions about her assault, which Amal did not appreciate. She wished her parents were more concerned and asked about her ordeal. "It just made it seem like it's not something you really talk about in general. Like it's a one and done conversation, kind of" (6: 322-324). Amal described future talk with her parents about her assault as almost nonexistent which she found to be hurtful when trying to heal from her assault.

Both positive and negative responses shaped the way survivors viewed their sexual assault, indicating that the communication about the assault was quite powerful and impactful on their perceptions of the trauma. Negative responses hurt the chances of survivors participating in future talk about sexual assault with their families. Participants explained that negative responses made them feel as though sexual assault was not something that families should talk about, leaving them feeling unsupported and unimportant. Although negative responses ranged from participant to participant, one overwhelmingly common response from confidants included messages of victim blaming $\left(\mathrm{RQ}^{4 \mathrm{a}}\right)$.

In Hispanic families, victim blaming emerged frequently and were often shaped by machismo or marianismo ideologies. Victim blaming was a particularly damaging negative response as it made participants feel as though they were somewhat responsible for their assault. This often drove a wedge between survivors and their families. In some cases, survivors completely discontinued communication with family members.

One victim blaming response that was shaped by machismo ideologies was that Hispanic men cannot be sexually assaulted. Emilio experienced victim blaming responses 
from his dad, stepdad, and extended family that he attributed to traditional Hispanic gender roles and machismo.

Well, I mean like as soon as my parents found out, it's like they had to tell everyone why I was in the hospital and they chose two different stories to go with. One that was my Stepdad's, one was my mom's. My Stepdad told our family that what happened was just a call for attention. That I was just lying about it because you know, these things don't happen to guys. And that I was just looking for attention and it was like me being mean to them because I was in the hospital costing them all these expenses and they eventually have to pay for them. And then the other story that was my mom said was that I was just very stressed about school and that's why I was in the hospital. But then, when the family members were asking about it and they heard that I was saying that I got sexually assaulted, I got a lot of mixed reactions. A lot of family members just didn't want to talk to me at all. (5: 243-260)

Between Emilio's family denial and victim blaming, future talk about the assault became very hostile. Emilio explained that not long after disclosing, he was called to testify against his perpetrators. When the trial was over, his relationship with his family deteriorated. He said that there was "so much friction between each other that I just had to leave the house. I couldn't stay there anymore" (5: 284-286). His dad and step-dad did not believe that he was assaulted because he was a man. His mother did not want to disagree with her husband, a marianismo ideal, which led to her not supporting Emilio through his ordeal. Machismo and marianismo negatively played a large role in his 
family's perspective on sexual assault. This example demonstrates that instances of victim blaming can have a severe impact on a survivor's relationship with their family. When participants received consistently culturally bound victim blaming messages over time, they often cut ties with those family members. For most participants, their family relationships have never been the same.

Culturally shaped victim blaming was also seen with female participants. According to marianismo values, women cannot be perpetrators of sexual assault as they are seen as submissive. Sophia was hesitant to disclose because her perpetrator was a female. She felt as though her family would not take her assault as seriously because they did not think that females can assault others, relating back to marianismo ideology.

One of the reasons I didn't want to tell who it was because everybody always pictured some male. Everyone always pictures a man. It's like they've never heard of a female abuser you know, they don't think that females are capable of that or something. And it just makes things harder. (4: 344-349)

Victim blaming was shaped by marianismo ideologies when it came to a Hispanic female's behavior when an assault occurred. Valeria received messages of victim blaming that were based on marianismo expectations her father had for her. He expressed disappointment in the fact that she had been drinking heavily the night she was assaulted. Although she predicted her father's response to her disclosure would be negative, she felt as though she needed her parents support so she chose to disclose. Her father's response confirmed her fears.

My mom didn't really say much and they're both I think a loss for words, but my dad eventually kind of took over the conversation, the feedback. It kind of did 
confirm my fear at first of putting the blame not necessarily just on me, but, um, going back to this is why I tell you not to drink, this is why you should be more careful. Which I know, and I usually am, but I told him, I was like, at that point I was fine one minute the next I wasn't. (7: 205-209)

Valeria went on to explain that her father's reaction left her feeling unsupported. She said that his response was shaped by his traditional marianismo beliefs that guided his views of appropriate behavior for women. Although Valeria's mom responded nonverbally, it seems as though her response was culturally-guided. Marianismo values support the idea that Hispanic women are supposed to agree with their husbands with no objection. By staying silent, Valeria's mom was staying true to those cultural values and engaging in what seemed like support for Valeria's father's response of victim blaming.

Victim blaming messages emerged with extended family in addition to immediate family. Although family members did not live with participants, their responses appear to be equally hurtful. These messages resulted in survivors questioning their own role in their assault. Miri received mostly supportive messages from her family after disclosing; however, she explained that some family members blamed her for her assault. "The half that didn't really believe me, made me feel like it wasn't valid or what I went through wasn't real" (3: 274-276). This led Miri to question her role in her assault.

Because you have two extreme sides on the assault itself, it was like, well, did I do something to, like help this happen to me? Was I, you know, like sexualizing myself or whatever? But I was, you know, at a young age, so, was I really? Or was I not? Like, you know, he was older than me, so he should have had the, you know, he should have had those thoughts in the first place and he should have 
been, you know, the adult to like not to do anything. Then it's always like you're always questioning yourself and like what you're saying or doing like did I do anything to say that it's okay for him to do? (3: 274-290)

Victim blaming was shown to leave a lasting impression on survivors and their subsequent family communication. Even after several years had passed since experiencing victim blaming, survivors' relationships with their family members had not recovered, meaning a survivor's relationship with their family was either still nonexistent or never the same. This demonstrates the significant role victim blaming plays in long term Hispanic family communication. Emilio explained that staying away from his family, even in present day, was the only way to protect himself from victim blaming messages.

Um, my grandma thought that whatever happened I caused it and then I had some cousins blame me for not being strong enough. So, all in all I just stayed away from my family as much as I could. To this day, they don't talk to me. (5: 258260)

Similarly, to Emilio’s experience, Miri stated that victim blaming from family members caused irreparable damage to her family's communication. She no longer speaks to family members who victim blamed her. "I guess it really took time to trust and be comfortable again. For some family, we still don't even talk because of it" (3: 310-312). She said that she lost trust in her family, and still today, some family members do not believe her, once again demonstrating how detrimental victim blaming is to family communication and future talk about sexual assault. In summary, positive and negative responses shaped future communication about sexual assault in Hispanic families. Only one participant reported experiencing a positive response from 
their family that encouraged future talk about the assault. All other participants experienced negative responses, including victim blaming, that discouraged future talk about assault. Societal rules, norms, and beliefs shape victim blaming attitudes (Alexander, 1980). This proves to be especially true with Hispanic families. Victim blaming messages are shaped by machismo and marianismo values that are specific to Hispanic families and detrimental to Hispanic family communication.

\section{Control Over Private Information}

In CPM, Axiom \#1 presumes that owners of private have the right to grant or deny access to private information. Further, the theory advises that once people share private information, both parties share responsibility for the appropriate management of the shared private information. In this study participants reported having little to no control over their private information. In some instances, loss of control occurred from the beginning when they were forced to disclose. At other times, they lost control after disclosing to a family member. Petronio (2010) states that privacy dilemmas are predicaments that provoke communication tension within families with no clear solution (p. 189). Due to their loss of control, many survivors confirmed that they experienced privacy dilemmas $\left(R^{5 a}\right)$.

$\mathrm{RQ}^{5 \mathrm{~b}}$ aimed to understand how Hispanic families managed privacy dilemmas. Participants demonstrated a lack of privacy coordination with family members, meaning that families experienced tensions with private information but did not attempt to resolve this tension with the survivor. Much of this tension was experienced because participants had no control over their private information once they disclosed or because they were forced to disclose to their families. Participants expressed a strong desire for control over 
their private information. The subthemes for this section on control over private information are lack of rule negotiation and forced disclosures.

\section{Lack of Rule Negotiation}

Participants often reported losing control over private information when they were not given the opportunity to negotiate privacy rules with confidants. Survivors lost control over their private information when their confidants shared their assault information with other family members without their permission, which was incredibly hurtful for participants. Many participants explained that rules were not collaborative in Hispanic families, and thus their experiences demonstrate the role of cultural values in privacy management. Hispanic families tend to hold patriarchal beliefs that dictate family life (Rafanello, 2004). In Hispanic families, patriarchal beliefs promote fatherhood which means there is no questioning a father or parent figure's authority, even regarding private information. This led to survivors feeling as though their parents and family had complete control over their disclosures which proved harmful to survivors who desired control.

After disclosing, survivors' parents tended to decide how their child's private information was managed, which was damaging to the survivors' healing process. For example, Emilio's parents immediately told the rest of the family without negotiating rules. Emilio had no say in which family members found out about his assault. "I mean as soon as my parents found out, it's like they had to tell everyone why I was in hospital and they chose two different stories to go with" (5: 243-245). Emilio further explains that his parents continued to tell his private information and alter it to avoid shaming the family that he was assaulted. His parents told family members he was hospitalized for stress from school. 
Similarly, Miri experienced a lack of rule negotiation with her family once she willingly disclosed to them.

Once I disclosed it was like an outburst of you know, they're going to pay for this. It was a frightening moment. It's like I wanted to talk about it to heal from it. Like for myself. But I didn't really care for him to have to pay for it in a way. (3: 174180)

Miri went on to explain that she did not feel as though she had a choice about what was to be done with her private information. "I didn't have control over it. Cause once it was said it just kind of took off from there" (3: 200-201). Miri stated that not having control over her private information or being able to set up rules made her ordeal worse to deal with. She did not have a say in what family members found out or what the next steps would be. She said it would have been ideal if her family asked her how she wanted to manage her own information about the assault.

In CPM, Axiom \#2 explains that holders of private information may feel a need for control over their private information and create rules for confidants which was true for participants. However, it appears that Axiom \#1 is not widely applicable to Hispanic families as survivors were not able to grant or deny access to other family members once they shared the information the first time. For Hispanic families, patriarchal values allow parents of survivors to manage private information without consideration. The promotion of patriarchal views allows for parents to take the reins of private information, and their children are not allowed objection to their parent's management of their private information. Simply put, survivors cannot question their parents. Consequently, participants said their families made them feel powerless. Participants did not perceive an 
opportunity to co-create rules for their private information with confidants. Loss of control over private information appears to be harmful to a survivor and further traumatizes them. Some participants reported a loss of control when they were forced to disclose to their families.

\section{Forced Disclosures}

Although CPM assumes that holders of private information have control over their private information, this assumption did not hold true for participants who were forced to disclose. Control over private information was completely lost for these participants.

For the participants in this study, forced disclosures occurred when a survivor under the age of 18 sought medical attention for their assault or confided in a school official. Participants explained that being forced to disclose to family members made their experience worse and traumatized them further. In fact, being forced to disclose made participants regret reaching out for help and led to privacy dilemmas. Sophia experienced loss of control over her private information once she disclosed to her school counselor that she had been sexually assaulted. She recalled that "I was forced to tell her because of, the whole DCFS stuff going on. So, it wasn't my choice to tell her [her mom], it was my choice to tell my counselor at school" (4: 116-119). She believes that the forced disclosure led to tension in her family that made her regret reaching out for help. Traditionally speaking, Hispanic families follow a "keep it in the family" mentality. Sophia explained that her mother did not know what to do with the private information and was angry that Sophia would tell someone outside of the family. Sophia said that “Once I told her [her mom], it was like, why didn't you tell me? Why did you tell all 
these people? Suddenly it was my fault for coming out and telling people what happened to me" (4: 175-178).

Because Sophia was assaulted by a family member, this posed a unique privacy dilemma. Her family was torn between protecting her and wanting to avoid hurting another family member by taking legal action. Sophia attributed this to the collectivist nature of Hispanic families. "Hispanics tend to be more family-based unlike here in the US, it's more individualistic. Hispanics it's more like we stick together type of thing" (4: 612-616). This example demonstrates that disclosing can be a very complex conversation to have when navigating cultural factors.

Similarly, Emilio recalled how difficult it was to cope with his assault once he was forced to disclose to his parents. He was hospitalized for a panic attack about a month after his assault. Since he was a minor, he was required to tell his parents about the assault, but he asked the doctors to disclose his assault to them.

It was the law in Illinois to send me to a psychiatric hospital for minors and that's when my parents had to find out. I had the doctors tell them. It was not the best way. It was not the way I would've wanted to disclose what happened. (5: 105-

Emilio explained that not having control over his private information was traumatic for him and made healing from his assault much more difficult, particularly because his parents then told other family members without his permission and distorted aspects of his story. They told family members either that he was lying to get attention or that he was in the hospital because school was causing him stress. Emilio felt that his family 
betrayed him; he also experienced an increase in feelings of losing control of his private information.

CPM assumes ownership over private information; however, for survivors of sexual assault, they do not always own their private information. Participants who were forced to disclose to family members felt an immediate loss of control over their private information. Both Sophia and Emilio stated that being forced to disclose was incredibly harmful to them and to their familial relationships. CPM typically frames privacy dilemmas as a confidant experience. However, participants who were forced to disclose to their family members described experiencing privacy dilemmas $\left(\mathrm{RQ}^{5 \mathrm{a}}\right)$.

In summary of the findings, Hispanic families manage sexual assault disclosures in unique ways due to cultural values. Current research focuses heavily on Hispanic survivors as disclosing to family members based on demographic factors such as biological sex. However, this study demonstrates that cultural values, such as machismo ideologies, and family communication about sex and sexual assault play a large role in if a survivor selects family members as confidants. Positive and negative responses from family members shaped survivors view of their experience; the negative responses, particularly victim blaming, appears to be detrimental to future family communication and to participants' perceptions of the assault. Finally, Hispanic families violated assumptions of CPM by not allowing participants to co-create rules due to patriarchal values. 


\section{CHAPTER V: DISCUSSION}

The purpose of this study was to better understand sexual assault disclosures in Hispanic families through the theoretical framework of Communication Privacy Management. The study focused on family communication about sexual assault prior to a sexual assault disclosure, during a sexual assault disclosure, and future talk about sexual assault. Five research questions guided this study. In the first research question I asked if Hispanic family conversations about sexual assault, prior to a sexual assault taking place, plays a role in a survivor's disclosure to their family. In research question 2 , I aimed to find what specific factors survivors consider when choosing to disclose to family member over others. The third research question asked how positive or negative responses play a role in future talk about the assault. In research question four, I explored how victim blaming emerges in responses to sexual assault disclose and what impact that has on family relationships. In the fifth and final research question, I asked what privacy dilemmas Hispanic survivors of assault experienced with their families and how they are managed.

\section{Summary of Findings}

In summary, I conducted a thematic analysis from the semi-structured interviews, in which three themes emerged. These themes were factors in confidant selection, confidant responses, and control over private information. By presenting these themes in accordance with the RQs, I was able to present a more holistic explanation of survivor's experiences when disclosing to their families. 


\section{Confidant Selection}

This study provides new insight into confidant selection and Hispanic families in terms of factors survivors consider before disclosing. CPM explains that confidant selection is a complex decision which showed to be true for those disclosing assault in Hispanic families. Participants tended to choose confidants who were open to talking positively about sex and sexual assault and tended to avoid disclosing to family members who were not open about sex and assault or who framed both negatively in their talk.

Hispanic family conversations about sex and sexual assault played a significant role in whether survivors chose to disclose to their family members $\left(R Q^{1}\right)$. This contradicts Villar and Concha (2012) and Finkenauer's (2004) research on family communication and sexual assault disclosures which puts an emphasis on demographics such as biological sex. Participants explained that their family's open or closed communication about sex and sexual assault prior to their disclosure was heavily considered as a factor in confidant selection $\left(\mathrm{RQ}^{2}\right)$. Specific family members who talked to survivors openly about sexual assault prior to their assault were more like to be chosen as a confidant.

Participants citing openness as a factor to confidant selection confirmed KennedyLightsey and Frisby's (2016) notion that families who encourage openness have an easier time processing sexual assault disclosures than those guided by parental authority. What is unique to Hispanic families is the importance of patriarchy values, which inherently gives parents authority. This finding suggests that Hispanic families may face bigger communicative barriers to be more open about topics such as sexual assault. The way a 
family communicated about sexual assault, or lack thereof, created preconceived notions for survivors as to how families would respond to their disclosure.

Participants tried to predict how family members would respond as a large factor in confidant selection. This supports that fear of a negative response can hinder a survivor from speaking about their assault (Durham, 2008). Perceived responses from family members were heavily shaped by prior family communication about sexual assault. Further demonstrating the importance of family communication and sexual assault disclosure while intertwining $\mathrm{RQ}^{1}$ and $\mathrm{RQ}^{2}$. All participants expressed a desire to disclose to their family, but some felt hesitant to do so because of the negative response they anticipated receiving from their family members. What is unique about Hispanic families is that the negative responses survivors predicted were often based on machismo and marianismo ideologies that their families promoted. These ideologies included a biological man's inability to be sexually assaulted or women causing an assault from drinking heavily. Predicted responses proved to be an important consideration to survivors. Equally important were confidant responses.

\section{Confidant Responses}

Confidant responses played a significant role in how survivors coped with their trauma and if future talk about the assault occurred in Hispanic families. Because confidant responses shaped a survivor's experience, it is representative of the collaborative nature of CPM. This study confirmed Orchowski, Untied, and Gidycz's (2013) suggestion that the way a confidant responds to a survivor's disclosure plays a role in how a survivor recovers from their trauma. In Hispanic families, it was more common for confidants to receive a negative reaction to their disclosure which was 
shaped by machismo or marianismo ideologies. Confidant responses were explored in the subthemes of positive responses, negative responses, and victim blaming.

Positive responses were not common in Hispanic families as only one participant identified receiving a positive response from family members. Positive responses made the survivor feel as though they could talk about their assault and recover from their trauma. The survivor also stated that positive responses to their disclosure aided in them seeking additional resources for their trauma such as therapy and legal action against their perpetrator. Positive responses allowed for the family to participate in future talk about the assault which the survivor found to be cathartic $\left(\mathrm{RQ}^{3}\right)$. Positive responses and the presence of future talk helped this family work through trauma together. In contrast to positive responses, the majority of participants experienced negative responses to their disclosures. Fehler-Cabral and Campbell (2013) argued that most survivors expect positive emotional support from family. In Hispanic families, all participants expressed a desire for a positive response; however, the majority did not expect a positive response due to their Hispanic family belief in machismo and marianismo.

Most participants received negative responses to disclosures, which they perceived as hurting their family communication. Researchers (e.g., Castaneda, 2018; Villar \& Concha, 2012) state that Hispanic families have negative responses to disclosures of sexual assault due to a variety of reasons. However, this study found that the reason behind a negative response was not wide ranged. Negative responses in Hispanic families almost always occurred because of beliefs in machismo or marianismo ideologies, which proved harmful for future family communication. For example, some participants cut off communication with family members entirely, eliminating the possibility of future talk about the assault $\left(\mathrm{RQ}^{3}\right)$. Some participants families 
responded with avoidance which participants found to be as hurtful as other negatives responses. Avoidance also eliminated future talk about the assault $\left(\mathrm{RQ}^{3}\right)$. Many confidant responses were intertwined with messages of victim blaming that were particularly harmful to survivors.

Within Hispanic families, messages of victim blaming emerged through machismo and marianismo ideologies $\left(\mathrm{RQ}^{4 \mathrm{a}}\right)$. For example, if a female survivor was drinking when she was assaulted, her family would respond to her disclosure with warnings of not drinking, rather than comfort, putting the responsibility on the survivor and not the perpetrator. Victim blaming proved detrimental to family communication as it often led to discontinuing relationships with family members and limited future talk about the assault $\left(\mathrm{RQ}^{4 \mathrm{~b}}\right)$. Eigenberg and Policastro (2016) suggest that biological women are more likely than biological men to be victim blamed based on their behavior during an assault. For biological Hispanic men this is not the case. A male participant explained that victim blaming messages emerged between him and his family as he was expected to fight off the perpetrator. This demonstrates that victim blaming is culturally bound and thus requires future research.

Confidant responses were examined through positive responses, negative responses, and victim blaming. These responses determined whether future talk about the assault occurred or not within Hispanic families $\left(\mathrm{RQ}^{3}\right)$. Those who received positive responses also reported the presence of future talk which they found to be helpful while healing from their trauma. Those who received negative responses reported the absence of future talk which was found to be harmful to survivors and detrimental to family communication $\left(\mathrm{RQ}^{3}\right)$. One particularly harmful response was victim blaming which was often shaped by machismo and marianismo ideologies. In addition to confidant 
responses, control over private information played a role in sexual assault disclosures in Hispanic families.

\section{Control Over Private Information}

The theme of control over private information demonstrates the importance of giving survivors control over their private information after disclosing. I found that there are many ways that CPM may not help us to understand Hispanic families and disclosure. For one, CPM assumes that original owners have the right to grant or deny access to private information. In Hispanic families, the ability to grant or deny access to their private information is not present when survivors are forced to disclose to their family. Hispanic families were shown to experience privacy dilemmas $\left(R^{5 a}\right)$. These privacy dilemmas were experienced primarily by disclosers who managed them predominantly by discontinuing communication with their family members $\left(R Q^{5 b}\right)$. This theme was explored through the subtheme of loss of control and then further explored through forced disclosure.

I found that participants who experienced loss of control contradicted assumptions of CPM. Axiom \#3 and \#4 assume that once one discloses private information, rules are co-created between disclosers and confidants (Petronio, 2013). However, there were no opportunities to co-create rules within Hispanic families. Participants explained that this was due their family's belief in patriarchal values in which parents have control over their children's private information and what to do with it. I found that participants faced privacy dilemmas when they lost control of their private information, contrary to current research that states privacy dilemmas are only experienced by confidants. Loss of control was hurtful to survivors who willingly 
disclosed their assault to their family members. However, some participants were forced to disclose their assault to their families.

Participants lost control further when they were forced to disclose their assault to their family. Participants who were forced to disclose their assault lost complete control over their private information, posing an unrecognized privacy dilemma. Petronio (2010) suggests that the best way families can cope with privacy dilemmas is through management strategies that help them to coordinate new privacy rules. Without the existence of previous privacy rules in Hispanic families, coordination of new privacy rules is not possible. As a result, survivors experience privacy dilemma tension and choose to discontinue communication with family members. Petronio (2002) notes that culture dictates how families cope with privacy, privacy dilemmas and the concept of privacy itself. This study demonstrates the detrimental toll that loss of control and culture takes on a survivor and their familial communication.

\section{Theoretical Implications}

This study highlights that sexual assault disclosures in Hispanic families is a culturally complex and multi-faceted communicative act. The data suggest that no two sexual assault disclosures are the same; however, participants faced similar issues before, during, and after disclosing. For almost all participants, considerations of familial confidants and confidants' responses were shaped by harmful machismo and marianismo ideologies. For both of these considerations, machismo and marianismo ideologies were to be harmful to the survivors' coping and perceptions of the assault and to their family communication. Although Petronio (2010) states in CPM that culture is a factor in disclosure, she does not go into depth about how culture plays a significant role in decisions about disclosing sexual assault in particular relationship types and minority families. 
The findings suggest that CPM may be too general of a theory for an analysis of managing private information in the context of sexual assault within specific cultures. The analysis shows that CPM has many assumptions that are not always applicable to survivors of sexual assault in Hispanic families. For one, CPM's Axiom \#1 predicts that owners of private information have the right to grant or deny access to private information. Castaneda (2018) suggests that Hispanic families view privacy much differently, and loss of control over private information is common due to patriarchal values. One way that participants lost privacy control was in the event of being legally mandated to disclose their assault to their families. Forced disclosures made survivor's recovery from trauma extremely difficult. Participants explained that their Hispanic families often responded with messages of blame rather than comfort, which they expected based on previous family communication and perceived to be based on the family's belief in machismo ideologies.

Additionally, Axiom \#3 and Axiom \#4 explains that owners of private information have a desire to control their private information, therefore they create rules. Participants also desired this control. However, not all participants had the opportunity to co-create rules or communicate their rules for privacy management after disclosure to their families. This is currently not considered in CPM. Strong patriarchal values in Hispanic cultures played a large role in the lack of rule creation. Although CPM notes that cultural values play a role in rule creation, many participants saw cultural values as eliminating their ability to create rules in their Hispanic families. In Hispanic families what parents say is final, and there is no room for objection even if the information is theirs. They lose control of their private information. CPM does not account for family dynamics that do not allow for creation or co-creation of rules between disclosers and confidants. CPM states that boundary turbulence is experienced when rules are violated by 
confidents. CPM does not identify turbulence experienced by family members when rules do not exist in the first place.

The scope of CPM proves to be limited when exploring the topic of Hispanic families and privacy dilemmas. The current definitions of privacy dilemmas need to be expanded. Petronio (2010) states that privacy dilemmas need further academic exploration. She notes that, "there are many other kinds of conditions that lead to violations, miscalculations, and missteps in need of exploration, particularly in families" (p. 178). In the context of sexual assault, Hispanic survivors experienced many missteps that their families took with their private information, including taking control away from survivors. Current research on privacy dilemmas are solely focused on confidants although they are said to be co-created. This raises the question of what disclosers experience when privacy dilemmas occur in Hispanic families. Overall, this study finds that control is a huge factor that is lacking in Hispanic families when survivors are recovering from sexual trauma.

\section{Practical Applications}

This study yields the possibility of practical application. This study could potentially help to create a guide tailored to the needs of Hispanic families related to navigating conversations about sexual assault. By providing families with the do's and don'ts of sexual assault disclosure and responses, tailored to their specific culture, this may increase the likelihood of positive responses. With positive responses, survivors will feel validated and supported, and these feelings may help increase their likelihood to report their assault. A guide could also point out the harmful role machismo and marianismo ideologies play in sexual assault disclosures. This guide could also be made available to school counselors and medical personnel to ensure it is known that not all 
cultures communicate about topics, such as sexual assault, in a similar manner. There are specific cultural influences involved, such as machismo ideologies. Further, medical provider training could be provided to address specific cultural needs of Hispanic communities when survivors seek medical attention for sexual assault. It is possible that this study could be a catalyst for destigmatizing sexual assault reporting among Hispanics. Finally, this study brings to light more critical ways to approach mandatory reporting, potentially creating a need for policy changes on mandatory reporting.

Hispanic family views on sexual assault are heavily based on machismo or marianismo ideologies. These ideologies shape negative responses that family members give to survivor's when disclosing sexual assault. These views are also shaped by media portrayals and stereotyping of Hispanics. There should be initiatives aimed at Hispanic women and families to help with media representations, for instance by developing more television programs with solely Hispanic cast members. By understanding the harm these messages cause to both a survivor and their familial relationships, family members may try to avoid such messages. They may adopt attitudes of caballerismo towards sexual assault over machismo attitudes. This study demonstrates the importance of Hispanic families having conversations about sexual assault prior to a disclosure. This may encourage Hispanic families to practice open communication on the topic to provide a comfortable environment in which survivors can disclose, if need be. This study could further benefit Hispanic families with future research on Hispanic families and sexual assault disclosures. 


\section{Limitations and Future Research}

There were a few limitations in this study to be noted. First, it was very difficult to recruit Hispanic participants. Participants explained that in Hispanic families, they have a "we do not talk about this" mentality when it comes to sexual assault which may have contributed to the difficulty of recruiting participants. Many of the organizations through which I attempted to recruit would not allow me to do so for various reasons, including a lack of compensation for participants and a perspective that the topic was inappropriate. The area in which the study was conducted posed a challenge, as there is a low population of Hispanic families living in the recruitment area. Perhaps with more time and an extended recruiting, I may have been able to conduct more interviews.

Additionally, it is possible that Hispanics may not subscribe to the word "survivor" or identify as a victim of sexual assault because of machismo and marianismo ideology in which Hispanic males are not able to be sexually assaulted and female Hispanics must be submissive. Additionally, media representation and reinforcement of Hispanic stereotypes may play a role in individuals not identifying as a survivor or victim since Hispanics are rarely framed as victims of crime. Normalized sexual violence in the Hispanic community may account for the lack of interviewees for this study. It may be wise for future researchers to reword the call for recruits to possibly attain more interviews. Instead of framing the call around sexual assault, it could be more inclusive to say unwanted touching or similar phrases.

In terms of future research, there is much to be explored theoretically for CPM in the context of sexual assault survivors in Hispanic families. CPM does not account for the absence of rule creation due to culture. Participants experienced loss of their private information or the opportunity to co-create rules. Many participants attributed losses of control to the overbearing 
nature of their family members. Hispanic families tend to ascribe to a patriarchal family in which parents have the final "say" and children are not to question their parents' decisions. When families apply their patriarchal attitudes to the context of sexual assault, they may be doing more harm than they realize. This calls for further research to be conducted on Hispanic families and their responses to disclosures.

Overall, CPM mentions culture as a decision criterion for confidant selection when understanding culture is imperative to using this theory as a whole. Culture plays a much larger role for various aspects of CPM in Hispanic families particularly with families who value machismo and marianismo ideologies. This leads one to wonder if cultural values play a larger role for other ethnicities when attempting to manage private information. Future research should focus on how minority families manage private information in the context of sexual assault disclosures. Because CPM does not account for culture-specific understanding of privacy management, reflected in this study through lack of rule creation due in part to patriarchal culture, being a member of the culture as a researcher could be helpful.

Future research should be done on mandatory disclosures for sexual assault survivors. Many participants explained that being forced to disclose to their family members was a traumatizing experience for them and hurt their relationships with family members. Perhaps the requirement of mandatory disclosures should be reconsidered or altered for minors. Participants expressed that they felt punished when they reached out for help but were then forced to disclose their assault against their will. Most participants desired power and control over their disclosure; however mandatory disclosures take away power and control.

Another framework through which I could have explored was cultural values and family communication patterns (Ritchie \& Fitzpatrick, 1990). It appears as though conformity is the 
most predominant family communication pattern among the Hispanic families who followed a machismo ideology. However, Rose's family was much more conversation-oriented and did not subscribe to machismo ideologies. Connecting cultural values with family communication patterns could help guide future research.

\section{Conclusion}

There is still much to be researched when it comes to sexual assault disclosures in Hispanic families. Through this study, I began exploring disclosures of sexual assault in Hispanic families. Using the theoretical framework of CPM, findings revealed that there is much progress to be made with this theory in the context of sexual assault disclosures in culturally diverse families.

The findings also suggest that a lack of culturally diverse research on sexual assault harms researchers' and practitioners' abilities to fully understand how to help those who have experienced sexual assault. Cultural factors played a large role in survivors disclosing to their family and the quality and existence of family relationships post-disclosure. Since a majority of research on sexual assault disclosures focus on Caucasian families, there is much work left to be done. This project has demonstrated that researchers have barely scratched the surface when it comes to understanding family communication and sexual assault disclosures, particularly within Hispanic families. 


\section{REFERENCES}

Ahrens, C. E. (2006). Being silenced: The impact of negative social reactions on the disclosure of rape. American Journal of Community Psychology, 38(3/4), 263-274. doi:10.1007/s10464-006-9069-9

Ahrens, C. E., Cabral, G., \& Abeling, S. (2009). Healing or hurtful: Sexual assault survivors' interpretations of social reactions from support providers. Psychology of Women Quarterly, 33, 81-94. doi:10.1111/j.1471-6402.2008.01476.x

Alexander, C. S. (1980). The responsible victim: Nurses' perceptions of victims of rape. Journal of Health and Social Behavior, 21(1), 22-33. doi:10.2307/213669

Arciniega, G. M., Anderson, T. A., Tovar-Blank, Z. G., Tracey, T. J. G., Estrada, F., \& Arciniega, G. M. (2015). Caballerismo factor. [Subscale from: Machismo Measure]. Journal of Multicultural Counseling and Development, 43, 191-205. doi: $10.1037 / 00220167.55 .1 .19$

Basinger, E. D., Wehrman, E. C., \& McAninch, K. G. (2016). Grief communication and privacy rules: Examining the communication of individuals bereaved by the death of a family member. Journal of Family Communication, 16(4), 285-302. doi:10.1080/15267431.2016.1182534

Bogen, K. W., Bleiweiss, K., \& Orchowski, L. M. (2018). Sexual violence is \#NotOkay: Social reactions to disclosures of sexual victimization on twitter. Psychology of Violence, 10(4), 1-9. doi:10.1037/vio0000192

Botta, R. A., \& Pingree, S. (1997). Interpersonal communication and rape: Women acknowledge their assaults. Journal of Health Communication, 2, 197-212. doi:10.1080/108107397127752 
Braun, V., \& Clarke, V. (2006). Using thematic analysis in psychology. Qualitative Research in Psychology, 3, 77-101. doi:10.1191/1478088706qp063oa

Bridge, M. C., \& Schrodt, P. (2013). Privacy orientations as a function of family communication patterns. Communication Reports, 26(1), 1-12. doi:10.1080/08934215.2013.773054

Brown, B. (2006). Shame resilience theory: A grounded theory study on women and shame. Families in Society: The Journal of Contemporary Social Services, 87, 43-52. doi:10.1606/1044-3894.3483

Castaneada, N. (2018). En boca cerrada no entran moscas. Flies don't enter closed mouths: A grounded theory study of Latinas' testimonios of child sexual abuse (Unpublished doctoral dissertation). University of Denver, Denver, CO.

Centers for Disease Control and Prevention. (2017). Preventing sexual violence. Retrieved from https://www.cdc.gov/violenceprevention/pdf/sv-factsheet.pdf

Durham, W. (2008). The rules-based process of revealing/concealing the family planning decisions of voluntarily child-free couples: A communication privacy management perspective. Communication Studies, 59(2), 132-147. doi:10.1080/10510970802062451

Eaton, A. A., Rose, S. M., Interligi, C., Fernandez, K., \& McHugh, M. (2016). Gender and ethnicity in dating, hanging out, and hooking up: Sexual scripts among Hispanic and White young adults. Journal of Sex Research, 53(7), 788-804. doi: $10.1080 / 00224499.2015 .1065954$

Eigenberg, H., \& Policastro, C. (2016). Blaming victims in cases of interpersonal violence: Attitudes associated with assigning blame to female victims. Women \& Criminal Justice, 26(1), 37-54. doi:10.1080/08974454.2014.997417 
Estrada, F., \& Arciniega, G. M. (2015). Positive masculinity among Latino men and the direct and indirect effects on well-being. Journal of Multicultural Counseling and Development, 43(3), 191-205. doi:10.1002/jmcd.12014.

Fehler-Cabral, G., \& Campbell, R. (2013). Adolescent sexual assault disclosure: The impact of peers, families, and schools. American Journal of Community Psychology, 52(1/2), 7383. doi:10.1007/s10464-013-9577-3

Finkenauer, C., Engels, R. E., Branje, S. T., \& Meeus, W. (2004). Relationship-specific disclosure. Journal of Marriage and Family, 6(6), 195-209. doi:10.1111/j.0022-2445.2004.00013.x-i1

Gray, N., Palileo, G., \& Johnson, D. (1993). Explaining rape victim blame: A test of attribution theory. Sociological Spectrum, 13, 377-392. doi:10.1080/02732173.1993.9982040

Genial. (2017). Is it Hispanic, Chicano/Chicana, Latino/Latino, or Latinx? Retrieved from: https://www.exploratorium.edu/sites/default/files/Genial_2017_Terms_of_Usage.pdf

Guba, E. G. (1978). Toward a methodology of naturalistic inquiry in educational evaluation. Los Angeles, CA: Center for the Study of Evaluation.

Harber, K. D., Williams, C. H., \& Podolski, P. (2015). Emotional disclosure and victim blaming. Emotion, 15(5), 603-614. doi:10.1037/emo0000056

Harvey, J. H., Orbuch, T. L., Chwalisz, K. D., \& Garwood, G. (1991). Coping with sexual assault: The roles of account-making and confiding. Journal of Traumatic Stress, 4(4), 515-531. doi:10.1007/bf00974587

Hayes, R. M., Lorenz, K., \& Bell, K. A. (2013). Victim blaming others: Rape myth acceptance and the just world belief. Feminist Criminology, 8(3), 202. doi: $10.1177 / 1557085113484788$ 
Herrera, Owens, \& Mallinckrodt. (2013). Traditional machismo and caballerismo as correlates of posttraumatic stress disorder, psychological distress, and relationship satisfaction in Hispanic veterans. Journal of Multicultural Counseling \& Development, 41, 21-35. doi: 10.1002/j.2161-1912.2013.00024.x

Kennedy-Lightsey, C. D., \& Frisby, B. N. (2016). Parental privacy invasion, family communication patterns, and perceived ownership of private information. Communication Reports, 29(2), 75-86. doi:10.1080/08934215.2015.1048477.

Lindlof, T. R., \& Taylor, B. C. (2011). Qualitative communication research methods (3rd ed.). Thousand Oaks, CA: Sage.

Lopez-Zeron, G. \& Blow, A. The role of relationships and families in healing from trauma. Journal of Family Therapy, 39, 580-597. doi:10.1111/1467-6427.12089

Mastro, D. E., \& Behm-Morazwitz, E. (2005). Latino representation on primetime television. Journalism \& Mass Communication Quarterly, 82(1), 110-130. doi: $10.1177 / 107769900508200108$

Mastro, Behm-Morawitz, \& Ortiz. (2007). The cultivation of social perceptions of Latinos: A mental models' approach. Media Psychology, 9, 347-365. doi: $10.1080 / 15213260701286106$

Mastro, D., \& Tukachinsky, R. (2012). Cultivation of perceptions of marginalized communities. In J. Shanahan, M. Morgan, \& N. Signorielli (Eds.), The cultivation differential: State of the art research in cultivation theory (pp. 38-60). New York \& Berlin: Peter Lang. 
McKibbin, G., Humphreys, C., \& Hamilton, B. (2017). "Talking about child sexual abuse would have helped me:" Young people who sexually abused reflect on preventing harmful sexual behavior. Child Abuse and Neglect, 70, 210-221. doi:10.1016/j.chiabu.2017.06.017

Middleton, A. V., McAninch, K. M., Pusateri, K. B., \& Delaney, A. L. (2016). "You just gotta watch what you say in those situations:" A normative approach to confidant communication surrounding sexual assault disclosure. Communication Quarterly, 64(2), 232-250. doi:10.1080/01463373.2015.1103290

O'Neil, J. M. (2008). Summarizing 25 years of research on men's gender role conflict using the gender role conflict scale: New research paradigms and clinical implications. The Counseling Psychologist, 36, 358-445. doi:10.1177/0011000008317057

Orbuch, T. L., Harvey, J. H., Davis, S. H., \& Merbach, N. J. (1994). Account-making and confiding as acts of meaning in response to sexual assault. Journal of Family Violence, 9 , 249-264. doi:10.1007/bf01531950

Orchowski, L. M., Untied, A. S., \& Gidycz, C. A. (2013). Social reactions to disclosure of sexual victimization and adjustment among survivors of sexual assault. Journal of Interpersonal Violence, 28(10), 2005-2023. doi:10.1177/0886260512471085

Petronio, S. (2002). Boundaries of privacy: Dialectics of disclosure. Albany, NY: SUNY Press

Petronio, S. (2007). Translational research endeavors and the practices of communication privacy management. Journal of Applied Communication Research, 35, 218-222. doi:10.1080/00909880701422443 
Petronio, S. (2010). Communication privacy management theory: What do we know about family privacy regulation? Journal of Family Theory and Review, 2(3), 175-196. doi:10.1111/j.1756-2589.2010.00052.

Petronio, S. (2013). Brief status report on communication privacy management theory. Journal of Family Communication, 13, 6-14. doi:10.1080/15267431.2013.743426

Petronio, S., \& Bantz, C. (1991). Controlling the ramifications of disclosure: "Don't tell anybody but ..." Journal of Language and Social Psychology, 10(4), 263-269. doi:10.1177/0261927X91104003

Petronio, S., Sargent, J., Andea, L., Reganis, P., \& Cichocki, D. (2004). Family and friends as healthcare advocates: Dilemmas of confidentiality and privacy. Journal of Social and Personal Relationships, 21(1), 33-52. doi:10.1177/0265407504039838

Pluretti, R., \& Chesebro, J. L. (2015). Managing privacy and the decision to disclose: Disclosures of sexual victimization. Communication Quarterly, 63(5), 550-567. doi:10.1080/01463373.2015.1078826

Rafanello, D. (2004). Can't touch my soul: A guide for lesbian survivors of child sexual abuse. Los Angeles, CA: Alyson Publications.

Ritchie, L. D., \& Fitzpatrick, M. A. (1990). Family communication patterns: Measuring intrapersonal perceptions of interpersonal relationships. Communication Research, 17, 523-544. doi: 10.1177/009365090017004007

Sheikh, S., \& McNamara, M. E. (2014). Insights from self-blame and victim blaming. Psychological Inquiry, 25(2), 241-244. doi:10.1080/1047840X.2014.904138

Sleath, E., \& Bull, R. (2010). Male rape victim and perpetrator blaming. Journal of Interpersonal Violence, 25(6), 969-988. doi:10.1177/0886260509340534 
Stephens, D., Eaton, A., \& Boyd, B. (2017). Hispanic college men's perceptions of appropriate strategies for initiating sexual intercourse with women. Sex Roles, 77(3-4), 239-253. doi: $10.1007 / \mathrm{s} 11199-016-0709-8$

Stephens, D. P., \& Eaton, A. A. (2014). The influence of masculinity scripts on heterosexual Hispanic college men's perceptions of female-initiated sexual coercion. Psychology of Men \& Masculinity, 15, 387-396. doi:10.1037/a0034639.

Taylor, S. C., \& Norma, C. (2013). The ties that bind: Family barriers for adult women seeking to report childhood sexual assault in Australia. Women's Studies International Forum, 37, 114-124. doi:10.1016/j.wsif.2012.11.004

Toller, P. W., \& McBride, M. C. (2013). Enacting privacy rules and protecting disclosure recipients: Parents' communication with children following the death of a family member. Journal of Family Communication, 13(1), 32-45. doi:10.1080/15267431.2012.742091

Tukachinsky, R., Mastro, D., \& Yarchi, M. (2017). The effect of prime-time television ethnic/racial stereotypes on Latino and Black Americans: A longitudinal national level study. Journal of Broadcasting \& Electronic Media, 61(3), 538-556. doi: $10.1080 / 08838151.2017 .1344669$

Rubin, H. J., \& Rubin, I. (2012). Qualitative interviewing: The art of hearing data. Thousand Oaks, CA: Sage.

Ullman, S. E., Filipas, H. H., Townsend, S. M., \& Starzynski, L. L. (2007). Psychosocial correlates of PTSD symptom severity in sexual assault survivors. Journal of Traumatic Stress, 20, 821-831. doi:10.1002/jts.20290 
Villar, M. E., \& Concha, M. (2012). Sex education and cultural values: experiences and attitudes of Latina immigrant women. Sex Education, 12(5), 545-554. doi:10.1080/14681811.2011.627733.

Wamsley, E. S. (2014). Marianismo. In D. J. Leonard \& C. Lugo-Lugo (Eds.), Latino history and culture: An encyclopedia (1st ed., pp. 314-316). New York, NY: M.E. Sharpe. 


\section{APPENDIX A: RESEARCH BOARD RECRUITMENT}

If you identify as a Hispanic who disclosed an incident of sexual assault to a family member, are comfortable speaking about the disclosure, and are at least 18 years old, please email Alyssa at amhern8@ilstu.edu to schedule your interview. With your permission, I will audio record the interview and I will delete the recording once I transcribe the interview. I will also change your name on the final thesis. 


\section{APPENDIX B: EMAIL RECRUITMENT}

Dear

I am a graduate student in the School of Communication and am conducting a research study on Hispanic family communication and sexual assault disclosure for my master's thesis. If you identify as a Hispanic, you have disclosed an incident of sexual assault to a family member, are comfortable speaking about the disclosure, and are at least 18 years old, then I request your participation.

You are invited to participate in an interview study regarding the communication processes that took place after your sexual assault. The interview may take place via phone, Facetime or Skype, or in person. Particularly, this study seeks to understand how prior family communication about sexual assault affects how one discloses their experiences. It also aims to understand how disclosures affect how one communicates after the assault with their families.

The interview will take approximately 30-60 minutes. It will be confidential (I will not share your identity with others). I will change your name on the final paper for this project. Your participation will be completely voluntary. You may decide not to answer any question, and you can stop the interview at any time. All questions will focus on conversations about sexual assault disclosure, not on the assault itself.

Please direct any questions and/or comments to my thesis advisor, Dr. Aimee Miller-Ott (aeott@ilstu.edu), or to me.

If you would like to participate, please contact me at the e-mail address below.

Sincerely,

Alyssa Hernandez

Graduate Student, School of Communication

Illinois State University

amhern8@ilstu.edu 
I am a graduate student in the School of Communication and am conducting a research study on Hispanic family communication and sexual assault disclosure for my master's thesis. If you identify as a Hispanic, you have disclosed an incident of sexual assault to a family member, are comfortable speaking about the disclosure, and are at least 18 years old, then I am inviting you to participate.

I will be conducting face-to-face, Skype/Facetime, and telephone interviews regarding the communication processes that takes place after a sexual assault. Particularly, this study seeks to understand how prior family communication about sexual assault affects how one discloses their experiences to family. It also aims to understand how disclosures affect how one communicates later with their families.

The interview will take about 30-60 minutes. It will be confidential (I will not share your identity with others). I will change your name on the final paper for this project. Your participation will be completely voluntary. You may decide not to answer any question, and you can stop the interview at any time. All questions will focus on conversations about sexual assault disclosure, not the assault itself. With your permission, I will audio record the interview and I will delete the recording once I transcribe the interview. I will also change your name on the final thesis.

Please direct any questions and/or comments to Dr. Aimee Miller-Ott (aeott@ilstu.edu) or to me. If you would like to participate, please contact me at the e-mail address below.

Sincerely,

Alyssa Hernandez

Graduate Student, School of Communication

Illinois State University

amhern8@ilstu.edu 


\section{APPENDIX D: FACEBOOK RECRUITMENT POST}

I am conducting a study for my thesis on Hispanics and sexual assault disclosure in families. I'm not asking people to speak about the assault. Instead, I'm interested in if and how people talked to their families about the assault and how their responses affected them. I am doing face-to-face, phone, or Skype/Facetime interviews that should last between 30 and 60 minutes

To participate, you must be Hispanic, 18 years or older, have disclosed an experience of sexual assault to at least one family member, and feel comfortable speaking about the disclosure. Your responses will be confidential. I will not share your identity or anything you say to others in a way that will identify you. With your permission, I will audio record the interview and I will delete the recording once I transcribe the interview. I will also change your name on the final thesis.

Anything you say answer will remain completely confidential. You can stop participating or skip questions any time you want. Please email me at amhern8@ilstu.edu if you want to participate. Please also send along this info to others and they can contact me directly to participate. 


\section{APPENDIX E: INFORMED CONSENT}

\section{Dear participants,}

I am a graduate student under the direction of Professor Aimee Miller-Ott in the School of Communication at Illinois State University. As part of the program requirement, I am conducting my thesis to better understand how prior family communication affects how one discloses sexual assault in Hispanic families. The study will also aim to understand if family communication is affected after a sexual assault disclosure.

Your participation will involve an open-ended interview about your family's conversations about the topic of sexual assault prior to disclosure and responses to your disclosure. The interview will be conducted face-to-face, over phone, or through Facetime/Skype and will take approximately 30 to 60 minutes. The interview will be audio recorded, with your permission, to ensure accuracy of recording your words. Recordings will be erased after transcription and will not have any links to your identity in the digital files. To participate you must be Hispanic, have disclosed an incident of sexual assault to at least one family member, are comfortable speaking about the disclosure, and are at least 18 years old.

Your participation in this study is voluntary. You may refuse to answer any question. You may skip or refuse to answer questions if you feel uncomfortable, and if you choose not to participate or to withdraw from the study at any time, there will be no penalty. Your responses are confidential - any information that might allow someone to identify you will not be disclosed. Your responses will be joined with those of other participants to develop themes for research presentation at conference or in publication.

As a participant, you may experience discomfort when talking about personal experiences. Participants may experience psychological or emotional pain. Participants who are distressed may contact Student Counseling Services at (309) 438-3655. Participants who are not ISU students may call the National Sexual Assault Hotline at 1-800-656-4673. Your comfort as a participant is of upmost importance. You will not be asked any questions about your specific experiences with sexual assault other than if the perpetrator was a family member. Respondents should not at any time disclose details about their assault. They should only disclose if the perpetrator was a family member and conversations surrounding their disclosure of sexual assault. As a participant, you must feel comfortable speaking about your disclosure and conversations that took place with family members. If at any point you feel as though the interview is too uncomfortable, the interview will immediately end. You can also skip questions at any time. While your instructor may know who does or does not agree to participate in the research before grades are posted, you will not be penalized if you choose to not participate.

There is a risk of breach of confidentiality in this study. Participants may experience a risk to their reputation should a breach of confidentiality occur. To minimize this risk, participants are encouraged to choose private locations in which to answer interview questions.

We need to make you aware that in certain research studies, it is our legal and ethical responsibility to report situations of child abuse, child neglect, or any life-threatening situation, 
illegal activity on the ISU campus, campus-controlled locations, or involving ISU students to appropriate authorities. However, we are not seeking this type of information in our study nor will you be asked questions about these issues.

Please direct any questions and/or comments to Dr. Aimee Miller-Ott (aeott@ilstu.edu) or myself. If you have any questions about your rights as a subject/participant in this research, or if you feel you have been placed at risk, you can contact the Research Ethics \& Compliance Office at Illinois State University at (309) 438-5527.

Sincerely,

Alyssa Hernandez, Graduate Student, School of Communication

Illinois State University

amhern8@ilstu.edu 


\section{APPENDIX F: INTERVIEW PROTOCOL}

Thank you for agreeing to participate in my study on family communication and sexual assault disclosure. I am going to ask you a series of open-ended regarding your family's communication about sexual assault prior to your disclosure, the communication surrounding your disclosure, and then I will ask you some questions about family conversations after your disclosure.

First, I'd like to ask you some background questions:

1. What is your age?

2. Your sex?

3. Were you raised with your biological family? If not, who raised you?

4. What family members do you live with?

5. How long ago were you assaulted?

6. How much time passed between your assault(s) and when you chose to disclose to your family?

7. Would you describe your family as close? If so, why? If not, why?

Now I'm going to ask you some questions about how your family talked about sexual assault prior to your disclosure.

9. What messages did you receive about sex/sexual assault growing up?

Follow up: Which family member(s) specifically talked about these topics? Why did they bring the topic up? In what situation? Were they talking about specific people?

10. Can you describe your family's attitude, if any, toward cases of sexual assault prior to your experience?

Follow up: Why do you believe that was your family's attitude?

11. Can you explain if the nature of talk and attitudes about sexual assault made for a comfortable setting in which to disclose your sexual assault?

12. How did your family's talk and attitudes about sexual assault prior to your disclosure influence the way you revealed your sexual assault?

Now I'd like to focus on your experiences disclosing to your family.

13. What factors did you consider when choosing which family member(s) to talk to about your experience?

14. Who was the first person you revealed your sexual assault to in your family and why?

15. What made you choose to talk about your assault to a family member over others?

Follow up: What challenges do you believe you faced when disclosing? 
16. Which member(s) of your family did you reveal your assault to?

17. When you revealed your assault, did you ever tell the person you were talking to what you wanted them to do with the information? (For instance, someone might say "don't tell a specific person" or "keep it to yourself."

Follow up: If you did tell them what to do with the information, did they follow these guidelines? If not, what occurred between you and family members who did not follow guidelines?

18. Did others in your family find out about your assault without you wanting them to? Can you describe how this happened?

Follow up: How did their learning about your assault that way impact your relationship with the person who found out?

\section{Now I'm going to ask you questions about your family conversations after you shared about your assault.}

19. How would you describe your family member(s) response(s) to your sharing?

Follow up: Did they vary by person or did all have a similar response? Please explain.

20. How has your family member(s)' responses to your sharing impacted your perspective on your sexual assault?

Follow up: How has their response(s) impacted how you communicate to others about your assault, if you have?

21. Were you ever made to feel as though you were responsible for your assault? Please provide examples if this applies. What, if anything, did people say or do to make you feel this way? How did you respond to what they said/did?

Follow up: How did these instances of blame impact your relationship with your family?

22. What were the biggest communicative changes you experienced when conversing with your family about the assault after you shared with them?

Follow up: In what ways, if any, did your sharing impact the closeness of your family?

23. Can you identify any ways in which your family communicated with you differently after you shared?

24. Can you identify any ways in which your family's perspective on the topic of sexual assault has changed due to your disclosure?

25. Do you believe your family's response to your disclosure was what you wanted at the time? Follow up: How do you think culture played a role in the way your family responded to your disclosure at the time?

26. If not already indicated during interview, ask if perpetrator was a family member or not. Is there anything else you would like to add about your family and your sexual assault disclosure? 